\title{
ÍNDICE DE FUENTES SOBRE LA RIOJA EN LAS ESCRIBANÍAS DE LA SECCIÓN DE CONSEJOS DEL ARCHIVO HISTÓRICO NACIONAL
}

\author{
Pedro Luis Lorenzo Cadarso*
}

\section{Objetivos del repertorio documental}

El conjunto de referencias documentales que se incluyen en este trabajo tienen su origen en el Proyecto de Historia de la Ciudad de Logroño, dirigido en el área de Historia Moderna por el Prof. José Luis Gómez Urdáñez. En el marco del mencionado proyecto a mí que correspondió realizar un vaciado lo más exhaustivo posible de los fondos que acerca de la ciudad y su entorno se custodiaban en el Archivo Histórico Nacional de Madrid. Luego, con una beca de Formación de Personal Investigador del Gobierno de La Rioja, pude continuar el trabajo durante otros cuatro años más.

Del conjunto de documentos localizados, una buena parte, la mayoría, son de fácil acceso al disponerse en la Sala o incluso están editados varios intrumentos de descripción archivística, tales como inventarios, catálogos y guías. Sin embargo, había un amplísimo conjunto documental, compuesto por los expedientes, judiciales en su mayoría, tramitados por los Consejos y cuya única referencia disponible eran los Libros de Matrícula en donde los escribanos del Consejo de Castilla asentaban cada asunto que entraba en su dependencia. Estos libros presentan notorias insuficiencias, fundamentalmente que su contenido no coincide con los documentos conservados, algunos perdidos, otros remitidos a Simancas y otros a otras dependencias administrativas o judiciales (fundamentalmente la Chancillería de Valladolid, para el caso de los pleitos judiciales).

\footnotetext{
* Departamento de Historia, Universidad de Extremadura. Este trabajo se ha realizado con una ayuda de investigación del P.R.I. de la Junta de Extremadura.
} 
Aunque ahora la situación ha mejorado, dado que se dispone en la Sala de Investigadores de una copia fotocopiada de los mencionados libros, su extensión (son varias decenas de volúmenes) y la no elaboración siquiera de un inventario, siguen haciendo útil un trabajo como el que aquí se presenta.

El objetivo central de este estudio es pues, en primer lugar, ofrecer al investigador una orientación inicial para su trabajo con los fondos de la Sección de Consejos del Archivo Histórico Nacional. De ahí que en el diseño de las referencias documentales haya primado el interés del historiador sobre otros referentes de tipo archivístico o diplomático.

En segundo lugar, y como objetivo más secundario, se intenta hacer una aportación al conocimiento de un conjunto documental hasta ahora casi desconocido por los profesionales que de una u otra manera hacen del patrimonio histórico documental su oficio.

Por último, ensayar una técnica de descripción archivística que, aun compartiendo métodos propios de la elaboración de inventarios y catálogos, no es ni una cosa ni otra. La archivística, tras el advenimiento de las nuevas tecnologías informáticas y de las metodologías actuales de clasificación, búsqueda y recuperación de la información, está obligada a renovar sus métodos de trabajo, especialmente los instrumentos de descripción hasta ahora seguidos.

\section{Metodología}

En la elaboración del índice se ha intentado adaptar el instrumento descriptivo a las necesidades más inmediatas del modernista, esto es, a ofrecer la posibilidad de localizar cada documento por los descriptores más usuales empleados en la investigación histórica: fechas, lugares, personas, instituciones y asuntos o materias. El resto de la información archivística y diplomática se obvia en aras de la concisión y la mencionada sumisión a la eficacia informativa.

De cada referencia documental se ofrecen una serie de datos informativos clasificados en ocho campos y cada asiento expresa una unidad de instalación archivística, no diplomática, de manera que puede incluir varios documentos (casi siempre será así) e incluso varios conjuntos documentales agrupados facticia o administrativamente. Los cuatro primeros campos son referencias archivísticas que permiten localizar el documento o documentos dentro de la Sección de Consejos o diplomáticas y cronológicas que nos acercan al tipo concreto de documento de que se trata:

1FECHA: Se expresa el año en arábigos y sirve como criterio de ordenación de los asientos.

2o SIGNATURA: Se indica en todo caso la signatura, salvo cuando el legajo dispone de una ordenación interna en expedientes, en cuyo caso se indican expresamente. 
$3^{\circ}$ UNIDAD DE INSTALACION: Se distinguen entre legajos y libros, a pesar de que en un buen número de casos los documentos se encuentran encuadernados en forma de códice. Esto quiere decir que hacemos referencia a la unidad de instalación archivística, no al formato en que aparece el documento o conjunto documental. Era una información imprescindible para poder cursar las peticiones en sala, dado que el AHN tiene signaturas independientes para libros y legajos.

4ำ TIPOLOGIA: Nos limitamos aquí a dar una información somera sobre la tipología documental, obviando los casos en que encontramos documentos anejos que escapan al tipo documental central que los agrupa.

Los cuatro últimos campos ofrecen información acerca del contenido:

5 ASUNTO: Referenciamos aquí la temática central de la unidad de instalación descrita, sin tomar en consideración temáticas colaterales o documentos anejos que tratan sobre asuntos diversos.

6은 POCION: Indicamos sólo las poblaciones riojanas y de entre éstas únicamente aquellas que protagonizan el asunto, obviando aquellas que aparecen tan sólo citadas.

$7^{\circ}$ ENTIDADES: Se indican las dependencias públicas o privadas que protagonizan o resuelven el asunto, dentro de La Rioja o en las diferentes instancias del Estado.

8ํㅡㄴ PENANA: Se citan a los personajes que tienen un papel protagonista en el asunto o cuando se trata de indiviudos notorios o importantes históricamente. 


\begin{tabular}{|c|c|c|c|c|c|c|c|}
\hline 1591 & 24.668 & Legajo & Pleito judicial & La villa contra la Mesta & Arnedo & $\begin{array}{l}\text { Concejo de la Mesta } \\
\text { Ayuntamiento } \\
\text { Consejo de Castilla }\end{array}$ & \\
\hline 1591 & 24.659 & Legajo & Petición & Reparación del puente & $\begin{array}{l}\text { Santo } \\
\text { Domingo de } \\
\text { la Calzada } \\
\end{array}$ & $\begin{array}{l}\text { Consejo de Castilla } \\
\text { Ayuntamiento }\end{array}$ & \\
\hline 1592 & 32.738 & Legajo & Pleito judicial & $\begin{array}{l}\text { Varias sentencias en el pletio por la } \\
\text { jurisdicción de la ciudad entre Nájera y el } \\
\text { duque. Amenazas contra los oficiales del } \\
\text { duque en la ciudad y negativas a admitir } \\
\text { sus nombramientos hasta } 1676 \text {. }\end{array}$ & Nájera & $\begin{array}{l}\text { Consejo de Castilla } \\
\text { Chancilleria de Valladolid } \\
\text { Ayuntamiento }\end{array}$ & $\begin{array}{l}\text { Juan Manrique de Lara } \\
\text { (duque de Nájera) }\end{array}$ \\
\hline 1594 & 24.652 & Legajo & Pleito judicial & $\begin{array}{l}\text { Pleito entre los vecinos y el convento sobre } \\
\text { quién tiene derecho a tomar residencia a } \\
\text { los oficiales del concejo }\end{array}$ & Anguiano & $\begin{array}{l}\text { Convento de Valvanera } \\
\text { Consejo de Castilla } \\
\text { Ayuntamiento }\end{array}$ & $\begin{array}{l}\text { Fray Hernando Marrón } \\
\text { (Abad de Valvanera) }\end{array}$ \\
\hline 1594 & 28.019 & Legajo & Pleito judicial & Reparación del puente sobre el rio lregua & $\begin{array}{l}\text { Villanueva de } \\
\text { Cameros }\end{array}$ & $\begin{array}{l}\text { Consejo de Castilla } \\
\text { Ayuntamiento }\end{array}$ & \\
\hline 1595 & 24.624 & Legajo & Pleito judicial & Ejecución indebida de una deuda & Logroño & Consejo de Castilla & $\begin{array}{l}\text { Ursula Gallego } \\
\text { Cristóbal Garcia } \\
\text { Avalos (alguacil } \\
\text { mayor) }\end{array}$ \\
\hline 1596 & 37.905 & Legajo & Pleito judicial & $\begin{array}{l}\text { Demanda contra el alguacil mayor de la } \\
\text { ciudad }\end{array}$ & Logroño & Consejo de Hacienda & Francisco Benito Mena \\
\hline 1596 & 27.996 & Legajo & Pleito judicial & $\begin{array}{l}\text { Disputas por el sistema de repartimiento de } \\
\text { los impuestos }\end{array}$ & $\begin{array}{l}\text { Torrecilla de } \\
\text { Cameros }\end{array}$ & $\begin{array}{l}\text { Ayuntamiento } \\
\text { Consejo de Castilla }\end{array}$ & \\
\hline 1596 & 38.030 & Legajo & Pleito judicial & $\begin{array}{l}\text { Las villas de Cervera y Alfaro contra el } \\
\text { fiscal del Consejo sobre bastimentos. }\end{array}$ & \begin{tabular}{|l|} 
Cenvera \\
Alfaro \\
\end{tabular} & Consejo de Hacienda & \\
\hline 1597 & 30.159 & Legajo & Pleito judicial & $\begin{array}{l}\text { Los albéitares contra La Redonda sobre el } \\
\text { derecho de mantener abiertos sus talleres } \\
\text { en la calle de la Herventia. }\end{array}$ & Logroño & $\begin{array}{l}\text { Iglesia Colegial de La } \\
\text { Redonda } \\
\text { Consejo de Castilla } \\
\end{array}$ & $\begin{array}{l}\text { Nuño de Ocampo } \\
\text { (corregidor) }\end{array}$ \\
\hline 1598 & 33.051 & Legajo & Pleito judicial & $\begin{array}{l}\text { La ciudad contra el convento de la Estrella } \\
\text { por el uso de los pastos de Villalobar. }\end{array}$ & $\begin{array}{l}\text { Villalobar } \\
\text { Santo } \\
\text { Domingo de } \\
\text { la Calzada }\end{array}$ & $\begin{array}{l}\text { Consejo de Castilla } \\
\text { Ayuntamiento } \\
\text { Convento de Santa Maria } \\
\text { de la Estrella }\end{array}$ & \\
\hline 1600 & 30.160 & Legajo & $\begin{array}{l}\text { Juicio de } \\
\text { comisión }\end{array}$ & $\begin{array}{l}\text { Denuncias por corrupción y monopolio de } \\
\text { los oficios municipales. }\end{array}$ & Fuenmayor & $\begin{array}{l}\text { Ayuntamiento } \\
\text { Consejo de Castilla }\end{array}$ & $\begin{array}{l}\text { Ldo. Velorado (juez de } \\
\text { comisión) }\end{array}$ \\
\hline 1600 & 28.365 & Legajo & Pleito judicial & $\begin{array}{l}\text { Disputas por preeminencias en las } \\
\text { procesiones entre el Obispo y el } \\
\text { Ayuntamiento. }\end{array}$ & Alfaro & $\begin{array}{l}\text { Consejo de Castilla } \\
\text { Ayuntamiento } \\
\text { Obispado de Tarazona }\end{array}$ & \\
\hline 1600 & 27.901 & Legajo & Pleito judicial & $\begin{array}{l}\text { El concejo contra el corregidor sobre su } \\
\text { sustitución. }\end{array}$ & $\begin{array}{l}\text { Santo } \\
\text { Domingo de } \\
\text { la Calzada }\end{array}$ & $\begin{array}{l}\text { Ayuntamiento } \\
\text { Consejo de Castilla } \\
\text { Corregimiento }\end{array}$ & \\
\hline
\end{tabular}




\begin{tabular}{|c|c|c|c|c|c|c|c|}
\hline 1601 & 30.168 & Legajo & Pleito judicial & $\begin{array}{l}\text { La villa contra la Mesta por acotar pastos } \\
\text { mesteños }\end{array}$ & $\begin{array}{l}\text { Arenzana de } \\
\text { Abajo }\end{array}$ & $\begin{array}{l}\text { Concejo de la Mesta } \\
\text { Ayuntamiento } \\
\text { Consejo de Castilla } \\
\text { Chancilleria de Valladolid }\end{array}$ & \\
\hline 1602 & 33.081 & Legajo & $\begin{array}{l}\text { Juicio de } \\
\text { comisión }\end{array}$ & $\begin{array}{l}\text { Ejecución de las deudas que la villa tenia } \\
\text { con el conde de Aguilar por el impago de } \\
\text { alcabalas. }\end{array}$ & Cervera & $\begin{array}{l}\text { Consejo de Castilla } \\
\text { Chancilleria de Valladalid } \\
\text { Adelantamiento de Burgos }\end{array}$ & \\
\hline 1602 & 28.366 & Legajo & Pleito judicial & $\begin{array}{l}\text { El concejo contra el Alcalde Mayor del } \\
\text { Adelantamiento de Burgos sobre } \\
\text { segregación de su jurisdicción. }\end{array}$ & Arenzana & $\begin{array}{l}\text { Adelantamiento de Burgos } \\
\text { Consejo de Castilla } \\
\text { Ayuntamiento }\end{array}$ & \\
\hline 1603 & 30.168 & Legajo & Memorial & $\begin{array}{l}\text { Denuncia de la corrupción de los regidores } \\
\text { ante el Consejo }\end{array}$ & Calahorra & $\begin{array}{l}\text { Consejo de Castilla } \\
\text { Ayuntamiento }\end{array}$ & Felipe de las Cuevas \\
\hline 1603 & 30.168 & Legajo & Pleito judicial & $\begin{array}{l}\text { Pleito entre el común y los regidores por la } \\
\text { reforma de las ordenanzas municipales. }\end{array}$ & Calahorra & $\begin{array}{l}\text { Consejo de Castilla } \\
\text { Ayuntamiento }\end{array}$ & \\
\hline 1603 & 37.921 & Legajo & $\begin{array}{l}\text { Juicio de } \\
\text { comisión }\end{array}$ & $\begin{array}{l}\text { Consumo de los oficios de regidores } \\
\text { perpetuos. }\end{array}$ & Alfaro & Ayuntamiento & $\begin{array}{l}\text { Ldo. Jubera Vergara } \\
\text { (juez de comisión) }\end{array}$ \\
\hline 1604 & 25.434 & Legajo & Pleito judicial & $\begin{array}{l}\text { Demanda entre Calahorra y sus aldeas por } \\
\text { haberse decidido roturar y vender parte de } \\
\text { los comunales. }\end{array}$ & \begin{tabular}{|l} 
Calahorra \\
Murillo de \\
Calahorra \\
Aldeanueva \\
de Ebro \\
Rincón de \\
Soto
\end{tabular} & $\begin{array}{l}\text { Ayuntamiento } \\
\text { Consejo de Castilla }\end{array}$ & \\
\hline 1605 & 37.930 & Legajo & Pleito judicial & $\begin{array}{l}\text { Privilegio de las parroquias de Viana de no } \\
\text { pagar tasas en la Aduana de Logroño }\end{array}$ & Logroño & $\begin{array}{l}\text { Consejo de Hacienda } \\
\text { Aduana de Logroño }\end{array}$ & \\
\hline 1606 & 33.112 & Legajo & Pleito judicial & $\begin{array}{l}\text { Denuncia de Aldeanueva contra Calahorra } \\
\text { por las requisas de trigo que ha hecho la } \\
\text { ciudad. }\end{array}$ & $\begin{array}{l}\text { Calahorra } \\
\text { Aldeanueva } \\
\text { de Ebro }\end{array}$ & $\begin{array}{l}\text { Consejo de Castilla } \\
\text { Ayuntamiento }\end{array}$ & \\
\hline 1606 & 3.227 & Libro & Asiento & $\begin{array}{l}\text { Motín antiseñorial contra el Conde de } \\
\text { Aguilar }\end{array}$ & Cervera & Consejo de Castilla & Conde de Aguilar \\
\hline 1607 & 24.751 & Legajo & $\begin{array}{l}\text { Memoriales e } \\
\text { informes }\end{array}$ & $\begin{array}{l}\text { Petición para poder usar en La Rioja el } \\
\text { vellón viejo }\end{array}$ & La Rioja & Consejo de Castilla & \\
\hline 1608 & 33.077 & Legajo & Pleito judicial & $\begin{array}{l}\text { Cornago denuncia a don Francisco de } \\
\text { Luna, señor de la villa, por maltratar al } \\
\text { alcalde ordinario hidalgo. }\end{array}$ & Cornago & $\begin{array}{l}\text { Consejo de Castilla } \\
\text { Ayuntamiento }\end{array}$ & $\begin{array}{l}\text { Francisco de Luna } \\
\text { (señor de Cornago) } \\
\text { Francisco Jiménez } \\
\text { Palomar (alcalde } \\
\text { ordinario) } \\
\end{array}$ \\
\hline 1608 & 24.814 & Legajo & Pleito judicial & Reconstrucción del puente de Logron̄o & Logroño & $\begin{array}{l}\text { Ayuntamiento } \\
\text { Consejo de Castilla }\end{array}$ & $\begin{array}{l}\text { Juan Solano (maestro } \\
\text { cantero) } \\
\text { Juan de la Riva } \\
\text { (maestro cantero) }\end{array}$ \\
\hline
\end{tabular}




\begin{tabular}{|c|c|c|c|c|c|c|c|}
\hline 1608 & 27.996 & Legajo & Pleito judicial & $\begin{array}{l}\text { Agresión contra una doncella por su } \\
\text { pretendiente }\end{array}$ & Logroño & Consejo de Castilla & $\begin{array}{l}\text { Felipa Falces } \\
\text { Francisco Anguiano }\end{array}$ \\
\hline 1608 & $\begin{array}{l}33.067 \\
33.068\end{array}$ & Legajo & Pleito judicial & $\begin{array}{l}\text { Calahorra contra su aldea Adeanueva por la } \\
\text { plantación de viñas }\end{array}$ & $\begin{array}{l}\text { Calahorra } \\
\text { Aldeanueva } \\
\text { de Ebro }\end{array}$ & $\begin{array}{l}\text { Ayuntamiento } \\
\text { Consejo de Castilla }\end{array}$ & \\
\hline 1608 & 28.304 & Legajo & Pleito judicial & $\begin{array}{l}\text { El concejo contra el arrendador del servicio } \\
\text { de Millones }\end{array}$ & Ventosa & $\begin{array}{l}\text { Consejo de Hacienda } \\
\text { Ayuntamiento }\end{array}$ & \\
\hline 1610 & 24.817 & Legajo & Pleito judicial & $\begin{array}{l}\text { Pelea entre los regidores durante la } \\
\text { celebración de las elecciones municipales }\end{array}$ & Logron̆o & $\begin{array}{l}\text { Consejo de Castilla } \\
\text { Ayuntamiento }\end{array}$ & \\
\hline 1610 & 24.817 & Legajo & Pleito judicial & $\begin{array}{l}\text { Enfrentamiento armado entre el corregidor y } \\
\text { varios soldados contra diversos vecinos. } \\
\text { Libelos. }\end{array}$ & Logroño & $\begin{array}{l}\text { Consejo de Castilla } \\
\text { Ayuntamiento }\end{array}$ & $\begin{array}{l}\text { Alonso Guiera } \\
\text { (corregidor) }\end{array}$ \\
\hline $16 \overline{10}$ & 37.930 & Legajo & Pleito judicial & Contrabando de tejidos & Logroño & $\begin{array}{l}\text { Aduana de Logroño } \\
\text { Consejo de Hacienda }\end{array}$ & $\begin{array}{l}\text { Antón Jiménez (correo } \\
\text { de Madrid) }\end{array}$ \\
\hline 1610 & $\begin{array}{l}33.072 \\
33.073\end{array}$ & Legajo & Pleito judicial & $\begin{array}{l}\text { El convento de Sta. María contra el } \\
\text { Obispado de Calahorra }\end{array}$ & Nájera & $\begin{array}{l}\text { Obispado de Calahorra } \\
\text { Convento de Santa Maria } \\
\text { la Real } \\
\text { Consejo de Castilla }\end{array}$ & \\
\hline 1611 & 30.197 & Legajo & $\begin{array}{l}\text { Juicio de } \\
\text { comisión }\end{array}$ & Libelos contra el alcalde ordinario & Fuenmayor & $\begin{array}{l}\text { Ayuntamiento } \\
\text { Consejo de Castilla }\end{array}$ & $\begin{array}{l}\text { Martín Nieto (alcalde } \\
\text { ordinario) }\end{array}$ \\
\hline 1612 & 33.909 & Legajo & Pleito judicial & Proceso por contrabando de pimienta & Calahorra & Consejo de Hacienda & Antón Amador \\
\hline 1612 & 29.589 & Legajo & Pleito judicial & $\begin{array}{l}\text { Disputas electorales entre hidalgos y } \\
\text { pecheros }\end{array}$ & Alesón & $\begin{array}{l}\text { Ayuntamiento } \\
\text { Consejo de Castilla }\end{array}$ & \\
\hline 1612 & 28.399 & Legajo & Pleito judicial & Rebaja en el encabezamiento de millones & Alfaro & $\begin{array}{l}\text { Consejo de Hacienda } \\
\text { Ayuntamiento }\end{array}$ & \\
\hline 1614 & 33.083 & Legajo & Pleito judicial & Reparación del puente & Arenzana & $\begin{array}{l}\text { Consejo de Castilla } \\
\text { Ayuntamiento }\end{array}$ & \\
\hline 1614 & $\begin{array}{l}33.087 \\
33.088 \\
33.089 \\
\end{array}$ & Legajo & Pleito judicial & Reparación del puente & $\begin{array}{l}\text { Cervera del } \\
\text { rio Alhama }\end{array}$ & $\begin{array}{l}\text { Ayuntamiento } \\
\text { Consejo de Castilla }\end{array}$ & \\
\hline 1614 & 33.935 & Legajo & Pleito judicial & $\begin{array}{l}\text { Pleito sobre los bienes de los moriscos } \\
\text { expuisados }\end{array}$ & Aguilar & Consejo de Hacienda & \\
\hline 1614 & 37.952 & Legajo & Pleito judicial & $\begin{array}{l}\text { Pleito sobre los bienes de los moriscos } \\
\text { expulsados }\end{array}$ & $\begin{array}{l}\text { Alfaro } \\
\text { Cervera de } \\
\text { rio Alhama }\end{array}$ & Consejo de Hacienda & \\
\hline 1615 & 42.715 & Legajo & $\begin{array}{l}\text { Visita de } \\
\text { escribanos }\end{array}$ & Inspección de las escribanias & Logroño & Consejo de Castilla & \\
\hline 1615 & 24.688 & Legajo & Pleito judicial & Aprobación de las ordenanzas & Avellaneda & $\begin{array}{l}\text { Consejo de Castilla } \\
\text { Ayuntamiento }\end{array}$ & \\
\hline 1616 & 33.930 & Legajo & Pleito judicial & $\begin{array}{l}\text { Concurso de acreedores contra los bienes } \\
\text { de Francisco Barrionuevo }\end{array}$ & Logroño & Consejo de Hacienda & Francisco Barrionuevo \\
\hline
\end{tabular}




\begin{tabular}{|c|c|c|c|c|c|c|c|}
\hline 1617 & 24.734 & Legajo & $\begin{array}{l}\text { Juicio de } \\
\text { residencia }\end{array}$ & Procesamiento del alcalde mayor & Logroño & Consejo de Castilla & $\begin{array}{l}\text { Doctor Angulo (alcalde } \\
\text { mayor) }\end{array}$ \\
\hline 1617 & 28.338 & Legajo & Pleito judicial & $\begin{array}{l}\text { Denuncia de Arnedo y Grávalos contra } \\
\text { Cornago por el uso de un monte } \\
\text { mancomunado }\end{array}$ & $\begin{array}{l}\text { Arnedo } \\
\text { Grávalos } \\
\text { Cornago } \\
\end{array}$ & Consejo de Castilla & \\
\hline 1618 & 28.348 & Legajo & Memorial & $\begin{array}{l}\text { Petición de rebaja del encabezamiento de } \\
\text { millones }\end{array}$ & $\begin{array}{l}\text { Torrecilla de } \\
\text { Cameros }\end{array}$ & Consejo de Hacienda & \\
\hline 1618 & 30.220 & Legajo & $\begin{array}{l}\text { Juicio de } \\
\text { comisión }\end{array}$ & $\begin{array}{l}\text { Lucha de bandos entre hidalgos y } \\
\text { pecheros. Intento de asesinato de un } \\
\text { hidalgo. Libelos }\end{array}$ & Arnedo & Consejo de Castilla & $\begin{array}{l}\text { Felipe de Arellano } \\
\text { (virrey de Navarra) }\end{array}$ \\
\hline 1618 & 15.217 & Legajo & $\begin{array}{l}\text { Consulta de } \\
\text { oficio }\end{array}$ & Consulta sobre el Priorato de Palacio & Logroño & $\begin{array}{l}\text { Iglesia de Santa María de } \\
\text { Palacio } \\
\text { Consejo de Castilla } \\
\text { Real Patronato } \\
\end{array}$ & \\
\hline 1619 & 37.958 & Legajo & Pleito judicial & Proceso por contrabando & Alcanadre & Consejo de Hacienda & \\
\hline 1619 & 28.020 & Legajo & $\begin{array}{l}\text { Juicio de } \\
\text { comisión }\end{array}$ & Pasquines y asesinatos contra los hidalgos & Arnedo & Consejo de Castilla & $\begin{array}{l}\text { Francisco Arellano } \\
\text { (hidalgo) } \\
\text { Familia Cuadra } \\
\end{array}$ \\
\hline 1619 & 25.469 & Legajo & Pleito judicial & El concejo contra el médico de la villa & Haro & $\begin{array}{l}\text { Consejo de Castilla } \\
\text { Ayuntamiento }\end{array}$ & \\
\hline 1619 & 27.904 & Legajo & Informe & Informe sobre la baja de la moneda & \begin{tabular}{|l} 
Nájera \\
\end{tabular} & Consejo de Hacienda & \\
\hline 1620 & 25.485 & Legajo & Petición & $\begin{array}{l}\text { El Ayuntamiento pide licencia para imponer } \\
\text { ciertos impuestos con los que sufragar la } \\
\text { construcción de tres nuevas fuentes en la } \\
\text { ciudad. }\end{array}$ & Calahorra & $\begin{array}{l}\text { Consejo de Castilla } \\
\text { Fiscalia del Consejo } \\
\text { Ayuntamiento }\end{array}$ & $\begin{array}{l}\text { Lucas Azpuru, } \\
\text { contratista de la obra. }\end{array}$ \\
\hline 1620 & 28.363 & Legajo & Petición & Reparación del puente & Lagunilla & $\begin{array}{l}\text { Consejo de Castilla } \\
\text { Ayuntamiento }\end{array}$ & \\
\hline 1621 & 37.978 & Legajo & Pleito judicial & $\begin{array}{l}\text { Denuncia contra el guarda del Puerto Seco } \\
\text { por no respetar el fuero eclesiástico. } \\
\text { Contrabando }\end{array}$ & Logroño & $\begin{array}{l}\text { Aduana } \\
\text { Consejo de Hacienda } \\
\text { Convento de La Merced } \\
\end{array}$ & \\
\hline 1621 & 29.611 & Legajo & \begin{tabular}{|l|} 
Pleito judicial \\
\end{tabular} & $\begin{array}{l}\text { Apropiación por Calahorra de unos términos } \\
\text { de Azagra y desviación del curso del rio } \\
\text { Ebro. }\end{array}$ & \begin{tabular}{|l|} 
Azagra \\
(Navarra) \\
Calahorra \\
\end{tabular} & Consejo de Castilla & \\
\hline 1621 & 15.661 & Legajo & \begin{tabular}{|l|} 
Pleito judicial \\
\end{tabular} & $\begin{array}{l}\text { Intromisión del Obispo en la provisión de un } \\
\text { beneficio en contra de los priviegios de los } \\
\text { parroquianos. }\end{array}$ & Logroño & $\begin{array}{l}\text { Tglesia de Santa Maria de } \\
\text { Palacio } \\
\text { Obispado de Calahorra } \\
\text { Patronato Real } \\
\text { Consejo de Castilla } \\
\end{array}$ & \\
\hline 1621 & 28.163 & Legajo & Pleito judicial & $\begin{array}{l}\text { Los vecinos se oponen a la construcción de } \\
\text { un nuevo templo para la iglesia Colegial. }\end{array}$ & Alfaro & $\begin{array}{l}\text { Iglesia Colegial } \\
\text { Consejo de Castilla } \\
\text { Ayuntamiento } \\
\end{array}$ & \\
\hline
\end{tabular}




\begin{tabular}{|c|c|c|c|c|c|c|c|}
\hline 1622 & 13.192 & Legajo & $\begin{array}{l}\text { Decreto de } \\
\text { gracia }\end{array}$ & $\begin{array}{l}\text { Concesión a don Francisco de Luna de la } \\
\text { alcaidia de Logroño y de la alcaidia de } \\
\text { sacas de los Obispados de Pamplona y } \\
\text { Calahorra }\end{array}$ & $\begin{array}{l}\text { Calahorra } \\
\text { Logroño }\end{array}$ & $\begin{array}{l}\text { Consejo de Castilla } \\
\text { Obispado de Calahorra }\end{array}$ & $\begin{array}{l}\text { Francisco de Luna } \\
\text { (Señor de soto) }\end{array}$ \\
\hline 1623 & 24.800 & Legajo & Pleito judicial & $\begin{array}{l}\text { Envío ilegal de ejecutores de deudas por } \\
\text { los oficiales del conde }\end{array}$ & Viguera & $\begin{array}{l}\text { Condado de Aguilar } \\
\text { Consejo de Castilla }\end{array}$ & $\begin{array}{l}\text { Juan Ramírez de } \\
\text { Arellano (conde de } \\
\text { Aguilar) }\end{array}$ \\
\hline 1623 & 29.623 & Legajo & $\begin{array}{l}\text { Juicio de } \\
\text { comisión }\end{array}$ & Contrabando de vellón con Navarra & Alfaro & $\begin{array}{l}\text { Consejo de Hacienda } \\
\text { Aduana de Alfaro }\end{array}$ & \\
\hline 1623 & 33.145 & Legajo & Pleito judicial & $\begin{array}{l}\text { El Ayuntamiento contre el alcalde mayor } \\
\text { por el derecho a examinar a los artesanos. }\end{array}$ & Alfaro & $\begin{array}{l}\text { Consejo de Castilla } \\
\text { Ayuntamiento }\end{array}$ & $\begin{array}{l}\text { Garcia Vallés } \\
\text { (procurador sindico } \\
\text { general). } \\
\text { Ldo. Antonio Vázquez } \\
\text { Medrano (alcalde } \\
\text { mayor) }\end{array}$ \\
\hline 1624 & 37.984 & Legajo & Pleito judicial & $\begin{array}{l}\text { Apelación ante el Consejo por parte del } \\
\text { estado general de Calahorra contra una } \\
\text { sentencia sobre exención del oficio de } \\
\text { cogedor de rentas. }\end{array}$ & Calahorra & Consejo de Hacienda & $\begin{array}{l}\text { Bartolomé Ferrer } \\
\text { (mercader y. } \\
\text { sombrerero) }\end{array}$ \\
\hline 1624 & 28.299 & Legajo & Pleito judicial & $\begin{array}{l}\text { Quejas por corrupción en el reparto del } \\
\text { agua de riego. }\end{array}$ & Logroño & $\begin{array}{l}\text { Consejo de Castilla } \\
\text { Ayuntamiento }\end{array}$ & \\
\hline 1624 & 37.978 & Legajo & Pleito judicial & Contrabando de moneda de vellón & Logroño & $\begin{array}{l}\text { Convento de la Merced de } \\
\text { Logroño } \\
\text { Consejo de Hacienda } \\
\text { Aduana de Logroño }\end{array}$ & \\
\hline 1624 & 24.989 & Legajo & $\begin{array}{l}\text { Juicio de } \\
\text { comisión }\end{array}$ & $\begin{array}{l}\text { Motín antiseńorial durante las elecciones a } \\
\text { oficiales de concejo. }\end{array}$ & Nájera & $\begin{array}{l}\text { Consejo de Castilla } \\
\text { Adelantamiento de Burgos } \\
\text { Ayuntamiento }\end{array}$ & Duque de Nájera \\
\hline 1624 & 33.149 & Legajo & Pleito judicia! & Pleito sobre el pago del servicio de millones & $\begin{array}{l}\text { Santo } \\
\text { Domingo de } \\
\text { la Calzada } \\
\end{array}$ & $\begin{array}{l}\text { Consejo de Hacienda } \\
\text { Ayuntamiento }\end{array}$ & \\
\hline 1625 & 37.985 & Legajo & Pleito judicial & Proceso por contrabando & Alcanadre & $\begin{array}{l}\text { Aduana } \\
\text { Consejo de Hacienda }\end{array}$ & \\
\hline 1625 & 37.984 & Legajo & \begin{tabular}{|l|} 
Pleito judicial \\
\end{tabular} & Sistema de gobierno del estado general & Calahorra & Junta de los Ocho & \\
\hline 1627 & 33.937 & Legajo & Pleito judicial & Proceso por contrabando & Calahorra & Consejo de Hacienda & Bernardo Cabrera \\
\hline 1627 & 33.938 & Legajo & Pleito judicial & $\begin{array}{l}\text { El Hospital de la Misericordia de Logroño } \\
\text { contra Murillo por impago de un censo } \\
\text { situado sobre los Propios de la vilia. }\end{array}$ & $\begin{array}{l}\text { Logroño } \\
\text { Murillo de Río } \\
\text { Leza }\end{array}$ & $\begin{array}{l}\text { Hospital de la Misericordia } \\
\text { de Logroño } \\
\text { Consejo de Hacienda }\end{array}$ & $\begin{array}{l}\text { Felipe de Soria } \\
\text { (capitán) }\end{array}$ \\
\hline 1627 & 24.841 & Legajo & Pleito Judicial & $\begin{array}{l}\text { Construcción de unas ventanas desde las } \\
\text { que los mercedarios podian ver el } \\
\text { dormitorio de las monjas }\end{array}$ & Logroño & $\begin{array}{l}\text { Convento de la Merced } \\
\text { Convento de San Pedro } \\
\text { (Agustinas) } \\
\text { Consejo de Castilia }\end{array}$ & \\
\hline
\end{tabular}




\begin{tabular}{|c|c|c|c|c|c|c|c|}
\hline 1627 & 15.661 & Legajo & Pleito judicial & $\begin{array}{l}\text { Provisión de un beneficio en la Parroquia } \\
\text { de Palacio }\end{array}$ & Logroño & $\begin{array}{l}\text { Iglesia de Santa María de } \\
\text { Palacio } \\
\text { Consejo de Castilla }\end{array}$ & $\begin{array}{l}\text { Francisco de Yanguas } \\
\text { y Peralta (clérigo) }\end{array}$ \\
\hline 1627 & 28.252 & Legajo & $\begin{array}{l}\text { Juicio de } \\
\text { comisión }\end{array}$ & $\begin{array}{l}\text { Lucha de bandos, con varios asesinatos, } \\
\text { entre hidalgos y pecheros. }\end{array}$ & Arnedo & $\begin{array}{l}\text { Consejo de Castilla } \\
\text { Adelantamiento de Burgos }\end{array}$ & $\begin{array}{l}\text { Condestable de } \\
\text { Castilla } \\
\text { Diego Lezana }\end{array}$ \\
\hline 1627 & 28.012 & Legajo & Pleito judicial & Pleito entre eclesiásticos & Calahorra & Consejo de Castilla & \\
\hline 1627 & 15.226 & Legajo & $\begin{array}{l}\text { Consulta de } \\
\text { oficio }\end{array}$ & Consulta sobre la Capilla del Santo Cristo & Logroño & $\begin{array}{l}\text { Patronato Real } \\
\text { Consejo de Castilla } \\
\text { Capilla del Santo Cristo }\end{array}$ & \\
\hline 1628 & 28.173 & Legajo & Pleito judicial & $\begin{array}{l}\text { Disputa entre eclesiásticos por el reparto de } \\
\text { los diezmos }\end{array}$ & Calahorra & $\begin{array}{l}\text { Cabildo } \\
\text { Consejo de Castilla }\end{array}$ & \\
\hline 1629 & 27.834 & Legajo & Pleito judicial & $\begin{array}{l}\text { Consumo del oficio de escribano perpetuo } \\
\text { del ayuntamiento por los vecinos }\end{array}$ & Calahorra & $\begin{array}{l}\text { Consejo de Castilla } \\
\text { Ayuntamiento } \\
\text { Pósito }\end{array}$ & $\begin{array}{l}\text { Antonio Martínez } \\
\text { Nieva (escribano de } \\
\text { ayuntamiento) }\end{array}$ \\
\hline 1629 & 24.851 & Legajo & $\begin{array}{l}\text { Juicio de } \\
\text { comisión }\end{array}$ & $\begin{array}{l}\text { Ataques de un grupo de bandoleros a } \\
\text { varios puebtos }\end{array}$ & $\begin{array}{l}\text { Arenzana } \\
\text { Valle del } \\
\text { Najerilla }\end{array}$ & $\begin{array}{l}\text { Consejo de Castilla } \\
\text { Adelantamiento de } \\
\text { Arenzana }\end{array}$ & \\
\hline 1629 & 28.421 & Legajo & Pleito judicial & $\begin{array}{l}\text { Negativa del concejo a admitir el } \\
\text { nombramiento del alcalde mayor. }\end{array}$ & Alfaro & $\begin{array}{l}\text { Consejo de Castilla } \\
\text { Ayuntamiento }\end{array}$ & $\begin{array}{l}\text { Garcia Vallés (alcalde } \\
\text { mayor) }\end{array}$ \\
\hline 1630 & 33.175 & Legajo & Pleito judicial & $\begin{array}{l}\text { Negativa del Ayuntamiento y del Obispado } \\
\text { a que el convento de la Trinidad se trasiade } \\
\text { al interior de la ciudad. }\end{array}$ & Logroño & $\begin{array}{l}\text { Consejo de Castilla } \\
\text { Ayuntamiento } \\
\text { Convento de la Santísima } \\
\text { Trinidad } \\
\text { Compañia de Jesús } \\
\text { Obispado }\end{array}$ & Nuncio Apostólico \\
\hline 1630 & 25.066 & Legajo & $\begin{array}{l}\text { Juicio de } \\
\text { comisión }\end{array}$ & $\begin{array}{l}\text { Represión contra un grupo de gitanos } \\
\text { nómadas. }\end{array}$ & $\begin{array}{l}\text { Santo } \\
\text { Domingo de } \\
\text { la Calzada }\end{array}$ & Consejo de Castilla & \\
\hline 1630 & 42.604 & Legajo & $\begin{array}{l}\text { Juicio de } \\
\text { residencia }\end{array}$ & Residencia al corregidor de Santo Domingo & $\begin{array}{l}\text { Santo } \\
\text { Domingo de } \\
\text { la Calzada } \\
\end{array}$ & $\begin{array}{l}\text { Consejo de Castilla } \\
\text { Ayuntamiento }\end{array}$ & \\
\hline 1630 & $\begin{array}{l}13.195 \\
\exp n^{0} 75\end{array}$ & Legajo & $\begin{array}{l}\text { Decreto de } \\
\text { gracia }\end{array}$ & $\begin{array}{l}\text { Concesión a don Francisco de Luna de la } \\
\text { alcaidia de Logroño y de la alcaidia de } \\
\text { sacas de los Obispados de Pamplona y } \\
\text { Calahorra }\end{array}$ & $\begin{array}{l}\text { Calahorra } \\
\text { Logroño }\end{array}$ & $\begin{array}{l}\text { Consejo de Castilla } \\
\text { Obispado de Calahorra }\end{array}$ & $\begin{array}{l}\text { Fernando de Luna } \\
\text { (Señor de Soto) }\end{array}$ \\
\hline 1633 & 15.232 & Legajo & $\begin{array}{l}\text { Consulta de } \\
\text { oficio }\end{array}$ & Consulta sobre el Priorato de Palacio & Logroño & $\begin{array}{l}\text { Patronato Real } \\
\text { Consejo de Castilla } \\
\text { glesia de Santa Maria de } \\
\text { Palacio }\end{array}$ & \\
\hline
\end{tabular}


$\pm$

\begin{tabular}{|c|c|c|c|c|c|c|c|}
\hline 1634 & 29.646 & Legajo & Pleito judicial & $\begin{array}{l}\text { Los procuradores del número perpetuos } \\
\text { contra los regidores por el precio excesivo } \\
\text { de sus oficios. }\end{array}$ & Logroño & $\begin{array}{l}\text { Ayuntamiento } \\
\text { Consejo de Castilla }\end{array}$ & \\
\hline 1634 & 38.024 & Legajo & Pleito judicial & Contrabando de madera & $\begin{array}{l}\text { Logroño } \\
\text { Agoncillo }\end{array}$ & $\begin{array}{l}\text { Aduana de Logroño } \\
\text { Consejo de Hacienda }\end{array}$ & \\
\hline 1634 & 41.414 & Legajo & Pleito judicial & Levas de soldados en la ciudad & Logroño & $\begin{array}{l}\text { Consejo de Guerra } \\
\text { Ayuntamiento }\end{array}$ & \\
\hline 1634 & 24.893 & Legajo & $\begin{array}{l}\text { Juicio de } \\
\text { comisión }\end{array}$ & $\begin{array}{l}\text { Enfrentamientos entre los vecinos de las } \\
\text { villas. }\end{array}$ & $\begin{array}{l}\text { Navarrete } \\
\text { Fuenmayor }\end{array}$ & Consejo de Castilla & \\
\hline 1636 & 30.306 & Legajo & $\begin{array}{l}\text { Juicio de } \\
\text { comisión }\end{array}$ & Alcalde ordinario maltrata a un cura & Anguiano & Consejo de Castilla & $\begin{array}{l}\text { Jorge Fernández } \\
\text { (cura) } \\
\text { Carlos de Avalos } \\
\text { (abogado, licenciado y } \\
\text { alcalde ordinario) }\end{array}$ \\
\hline 1637 & 15.661 & Legajo & Pleito judicial & $\begin{array}{l}\text { Elecciones a Rector de la parroquia de } \\
\text { Palacio. }\end{array}$ & Logroño & $\begin{array}{l}\text { Tglesia de Santa Maria de } \\
\text { Palacio } \\
\text { Consejo de Castilla } \\
\end{array}$ & \\
\hline 1637 & 41.412 & Legajo & Pleito judicial & $\begin{array}{l}\text { Arbitrios impuestos para la paga del } \\
\text { servicio de los } 2 \text { millones. }\end{array}$ & Calahorra & $\begin{array}{l}\text { Consejo de Hacienda } \\
\text { Ayuntamiento }\end{array}$ & \\
\hline 1638 & 24.936 & Legajo & $\begin{array}{l}\text { Visita de } \\
\text { Sacas y } \\
\text { Cosas } \\
\text { Vedadas }\end{array}$ & Inspección a los mercaderes de Logroño & Logroño & Consejo de Hacienda & $\begin{array}{l}\text { Licenciado Briones } \\
\text { (Juez de comisión) }\end{array}$ \\
\hline 1638 & 28.058 & Legajo & Pleito judicial & Querella criminal & Anguiano & Consejo de Castilla & \\
\hline 1639 & 24.945 & Legajo & Pleito judicial & $\begin{array}{l}\text { Consumo de los oficios de regidores } \\
\text { perpetuos. }\end{array}$ & Nájera & $\begin{array}{l}\text { Consejo de Castilla } \\
\text { Ayuntamiento }\end{array}$ & $\begin{array}{l}\text { Andrés Lesa Angulo } \\
\text { (Procurador del } \\
\text { común) }\end{array}$ \\
\hline 1639 & 30.299 & Legajo & Pleito judicial & $\begin{array}{l}\text { Intento de la villa de eximirse de la } \\
\text { jurisdicción del Adelantamiento de Burgos }\end{array}$ & San Asensio & $\begin{array}{l}\text { Adelantamiento de Burgos } \\
\text { Consejo de Castilla }\end{array}$ & \\
\hline 1639 & $\begin{array}{l}13.198 \\
\exp n^{\circ} 7 \\
\end{array}$ & Legajo & $\begin{array}{l}\text { Decreto de } \\
\text { gracia }\end{array}$ & $\begin{array}{l}\text { Concesión al marqués de Montara del } \\
\text { Privilegio de Reserva en Arnedo }\end{array}$ & Arnedo & Consejo de Castilla & Marqués de Montara \\
\hline 1640 & 25.066 & Legajo & Pleito judicial & $\begin{array}{l}\text { Lucha de bandos. Perpetuación de las } \\
\text { escribanias. }\end{array}$ & Haro & $\begin{array}{l}\text { Consejo de Castilla } \\
\text { Ayuntamiento } \\
\text { Escribanias del número }\end{array}$ & $\begin{array}{l}\text { Antonio de San } \\
\text { Vicente (familiar del } \\
\text { Santo Oficio) }\end{array}$ \\
\hline 1641 & 28.034 & Legajo & Pleito judicial & Cuentas del Pósito de Santo Domingo & $\begin{array}{l}\text { Santo } \\
\text { Domingo de } \\
\text { la Calzada } \\
\end{array}$ & $\begin{array}{l}\text { Ayuntamiento } \\
\text { Consejo de Castilla }\end{array}$ & \\
\hline 1642 & 41.412 & Legajo & Informe & $\begin{array}{l}\text { Efectos en la ciudad de la baja de la } \\
\text { moneda }\end{array}$ & Logroño & Consejo de Hacienda & $\begin{array}{l}\text { Francisco Fernández } \\
\text { Rioja (alcalde mayor) }\end{array}$ \\
\hline
\end{tabular}




\begin{tabular}{|c|c|c|c|c|c|c|c|}
\hline 1642 & 15.661 & Legajo & Pleito judicial & $\begin{array}{l}\text { Modificación del sistema de provisión de } \\
\text { beneficios en la parroquia de Palacio. }\end{array}$ & Logroño & $\begin{array}{l}\text { Iglesia de Santa María de } \\
\text { Palacio } \\
\text { Patronato Real } \\
\text { Consejo de Castilla }\end{array}$ & \\
\hline 1642 & 32.368 & Legajo & Pleito judicial & Expolio del Obispo de Calahorra & $\begin{array}{l}\text { Calahorra } \\
\text { Logroño }\end{array}$ & $\begin{array}{l}\text { Consejo de Castilla } \\
\text { Obispado de Calahorra }\end{array}$ & $\begin{array}{l}\text { Gonzalo Chacón } \\
\text { (Obispo de Calahorra) }\end{array}$ \\
\hline 1642 & 28.006 & Legajo & $\begin{array}{l}\text { Juicio de } \\
\text { comisión }\end{array}$ & $\begin{array}{l}\text { El común contra lo regidores por las } \\
\text { cuentas de los Propios }\end{array}$ & Fuenmayor & $\begin{array}{l}\text { Ayuntamiento } \\
\text { Consejo de Castilla }\end{array}$ & \\
\hline 1642 & 28.401 & Legajo & Pleito judicial & $\begin{array}{l}\text { La Mesta contra Murillo de Río Leza por } \\
\text { realizar roturaciones y plantar viñas en su } \\
\text { término }\end{array}$ & $\begin{array}{l}\text { Murillo de rio } \\
\text { Leza }\end{array}$ & $\begin{array}{l}\text { Concejo de la Mesta } \\
\text { Consejo de Castilla } \\
\text { Ayuntamiento }\end{array}$ & \\
\hline 1642 & 25.581 & Legajo & Pleito judicial & $\begin{array}{l}\text { Disputas por la venta de las alcabalas de la } \\
\text { villa }\end{array}$ & Autol & $\begin{array}{l}\text { Consejo de Hacienda } \\
\text { Ayuntamiento }\end{array}$ & \\
\hline 1642 & 27.842 & Legajo & Pleito judicial & Disputa por roturaciones en los comunales & Autol & $\begin{array}{l}\text { Consejo de Castilla } \\
\text { Ayuntamiento }\end{array}$ & \\
\hline 1643 & 27.918 & Legajo & Pleito judicial & Expolio del Obispo & Logroño & $\begin{array}{l}\text { Consejo de Castilla } \\
\text { Obispado de Calahorra }\end{array}$ & Juan Piñero (Obispo) \\
\hline 1643 & 42.606 & Legajo & $\begin{array}{l}\text { Juicio de } \\
\text { residencia }\end{array}$ & Residencia al corregidor de Santo Domingo & $\begin{array}{l}\text { Santo } \\
\text { Domingo de } \\
\text { la Calzada }\end{array}$ & $\begin{array}{l}\text { Consejo de Castilla } \\
\text { Ayuntamiento }\end{array}$ & \\
\hline 1644 & 25.600 & Legajo & Pleito judicial & $\begin{array}{l}\text { Pleito por la negativa del Ayuntamiento a } \\
\text { admitir a los mercaderes como regidores }\end{array}$ & Logroño & $\begin{array}{l}\text { Consejo de Hacienda } \\
\text { Ayuntamiento }\end{array}$ & $\begin{array}{l}\text { José Echegaray } \\
\text { (mercader) }\end{array}$ \\
\hline 1644 & 42.641 & Legajo & $\begin{array}{l}\text { Visita de } \\
\text { escribanos }\end{array}$ & Inspección de los escribanos de la ciudad & Logroño & Consejo de Castilla & $\begin{array}{l}\text { Antonio Astorga (juez } \\
\text { de comisión y oidor del } \\
\text { Consejo de Castilla) }\end{array}$ \\
\hline 1644 & 42.640 & Legajo & $\begin{array}{l}\text { Visita de } \\
\text { escribanos }\end{array}$ & Proceso contra Bernardo Abaygar & togroño & Consejo de Castilla & $\begin{array}{l}\text { Bemardo Abaygar } \\
\text { (escribano del número) } \\
\text { Antonio Astorga (juez } \\
\text { visitador) }\end{array}$ \\
\hline 1644 & 28.034 & Legajo & Pleito judicial & Cuentas de los arbitrios & Calahorra & $\begin{array}{l}\text { Ayuntamiento } \\
\text { Consejo de Castilla }\end{array}$ & \\
\hline 1644 & 28.034 & Legajo & Pleito judicial & Cuentas de los arbitrios & $\begin{array}{l}\text { Cervera del } \\
\text { río Alhama }\end{array}$ & $\begin{array}{l}\text { Ayuntamiento } \\
\text { Consejo de Castilla }\end{array}$ & \\
\hline 1644 & $\begin{array}{l}13.201 \\
\exp . \mathrm{n}^{\circ} 65\end{array}$ & Legajo & $\begin{array}{l}\text { Decreto de } \\
\text { gracia }\end{array}$ & $\begin{array}{l}\text { Concesión a don Alvaro Pérez del oficio de } \\
\text { regidor preeminente de Alfaro }\end{array}$ & Alfaro & $\begin{array}{l}\text { Consejo de Castilla } \\
\text { Ayuntamiento }\end{array}$ & Alvaro Pérez \\
\hline 1645 & 42.579 & Legajo & Pleito judicial & Asesinato de un vecino & Arnedo & Consejo de Castilla & \\
\hline 1645 & 25.695 & Legajo & $\begin{array}{l}\text { Acta de } \\
\text { Concejo } \\
\text { abierto } \\
\end{array}$ & $\begin{array}{l}\text { Votaciones en concejo abierto sobre el } \\
\text { consumo de los oficios de regidores } \\
\text { perpetuos. }\end{array}$ & Logroño & $\begin{array}{l}\text { Consejo de Castilla } \\
\text { Ayuntamiento }\end{array}$ & \\
\hline 1645 & 25.581 & Legajo & Pleito judicial & $\begin{array}{l}\text { Venta de las alcabalas, propiedad del } \\
\text { señor, a la villa }\end{array}$ & Autol & Consejo de Hacienda & $\begin{array}{l}\text { Jerónimo del Aguila } \\
\text { (Tesorero de la Reina } \\
\text { y Señor de Autol) }\end{array}$ \\
\hline
\end{tabular}




\begin{tabular}{|c|c|c|c|c|c|c|c|}
\hline 1645 & 28.297 & Legajo & Pleito judicial & $\begin{array}{l}\text { Quejas contra el ejecutor del Consejo de } \\
\text { Hacienda. }\end{array}$ & Alfaro & $\begin{array}{l}\text { Consejo de Hacienda } \\
\text { Ayuntamiento }\end{array}$ & \\
\hline 1645 & 23.738 & Legajo & $\begin{array}{l}\text { Juicio de } \\
\text { comisión }\end{array}$ & Denuncias por abusos del alcalde mayor & Alfaro & $\begin{array}{l}\text { Consejo de Castilla } \\
\text { Corregimiento de Logroño }\end{array}$ & $\begin{array}{l}\text { Pedro Enríquez del } \\
\text { Bayo (alcalde mayor) }\end{array}$ \\
\hline 1645 & 27.918 & Legajo & Pleito judicial & $\begin{array}{l}\text { Enfrentamientos entre los regidores } \\
\text { perpetuos y el clero local. }\end{array}$ & Alfaro & $\begin{array}{l}\text { Ayuntamiento } \\
\text { Cabildo } \\
\text { Consejo de Castilla } \\
\text { Hospital } \\
\end{array}$ & $\begin{array}{l}\text { Marcos Pullera } \\
\text { (sacristán del Hospital) }\end{array}$ \\
\hline 1645 & 27.906 & Legajo & Pleito judicial & $\begin{array}{l}\text { Consumo de los oficios de regidores } \\
\text { perpetuos. Cuentas de Propios y padrón } \\
\text { municipal. }\end{array}$ & Alfaro & $\begin{array}{l}\text { Ayuntamiento } \\
\text { Consejo de Castilla }\end{array}$ & \\
\hline 1646 & 7.158 & Legajo & $\begin{array}{l}\text { Consulta de } \\
\text { oficio }\end{array}$ & $\begin{array}{l}\text { El Consejo de Castilla informa al rey del } \\
\text { estado de los pleitos entre los regidores } \\
\text { perpetuos de Logroño y el común. Contiene } \\
\text { respuesta del rey. }\end{array}$ & Logroño & $\begin{array}{l}\text { Consejo de Castilla } \\
\text { Ayuntamiento } \\
\text { Obispado de Calahorra }\end{array}$ & $\begin{array}{l}\text { Felipe IV (rey de } \\
\text { España) }\end{array}$ \\
\hline 1646 & 7.163 & Legajo & $\begin{array}{l}\text { Consulta de } \\
\text { oficio }\end{array}$ & $\begin{array}{l}\text { El Consejo informa al rey de las quejas de } \\
\text { los vecinos sobre los abusos de los } \\
\text { regidores en el reparto del agua de riego. }\end{array}$ & Alfaro & $\begin{array}{l}\text { Ayuntamiento } \\
\text { Consejo de Castilla }\end{array}$ & $\begin{array}{l}\text { Felipe IV (rey de } \\
\text { España) } \\
\text { José Donamaria } \\
\text { (corregidor) }\end{array}$ \\
\hline 1647 & 27.918 & Legajo & $\begin{array}{l}\text { Juicio de } \\
\text { residencia }\end{array}$ & $\begin{array}{l}\text { Acusaciones de los regidores contra el } \\
\text { alcalde mayor. }\end{array}$ & Logroño & $\begin{array}{l}\text { Ayuntamiento } \\
\text { Consejo de Castilla }\end{array}$ & $\begin{array}{l}\text { Pedro Badarán } \\
\text { (alcalde mayor) }\end{array}$ \\
\hline 1647 & 7.159 & Legajo & $\begin{array}{l}\text { Consulta de } \\
\text { oficio }\end{array}$ & $\begin{array}{l}\text { Compra de juros por los oficiales de la } \\
\text { Inquisición }\end{array}$ & Logroño & $\begin{array}{l}\text { Consejo de Castilla } \\
\text { Inquisición de Logroño }\end{array}$ & \\
\hline 1647 & 28.036 & Legajo & Pleito judicial & Destitución del alcalde mayor de Alfaro. & \begin{tabular}{|l|} 
Alfaro \\
Logroño
\end{tabular} & Consejo de Castilla & $\begin{array}{l}\text { Ldo. Pedro Badarán } \\
\text { (alcalde mayor de } \\
\text { Logroño) } \\
\text { Antonio Vázquez } \\
\text { (alcaide mayor de } \\
\text { Alfaro) } \\
\end{array}$ \\
\hline 1647 & 27.918 & Legajo & Pleito judicial & $\begin{array}{l}\text { Regidores perpetuos intentan que el alcalde } \\
\text { mayor recién nombrado continúe otro } \\
\text { trienio. }\end{array}$ & Alfaro & $\begin{array}{l}\text { Consejo de Castilla } \\
\text { Ayuntamiento }\end{array}$ & $\begin{array}{l}\text { Pedro Badarán } \\
\text { (alcalde mayor) }\end{array}$ \\
\hline 1647 & 25.360 & Legajo & $\begin{array}{l}\text { Juicio de } \\
\text { comisión }\end{array}$ & $\begin{array}{l}\text { Asalto del convento jerónimo de la Estrella } \\
\text { por los vecinos y malos tratos a criados de } \\
\text { los frailes. }\end{array}$ & San Asensio & $\begin{array}{l}\text { Conveto de Santa María } \\
\text { de la Estrella } \\
\text { Consejo de Castilla } \\
\text { Ayuntamiento } \\
\end{array}$ & \\
\hline 1647 & 3.199 & Libro & Asiento & Asesinato de un vecino & Navarrete & Consejo de Castilla & Juan Ceballos \\
\hline
\end{tabular}




\begin{tabular}{|c|c|c|c|c|c|c|c|}
\hline 1647 & 25.627 & Legajo & Pleito judicial & $\begin{array}{l}\text { Confirmación por el Consejo de las } \\
\text { ordenanzas de la villa }\end{array}$ & Haro & $\begin{array}{l}\text { Consejo de Castilla } \\
\text { Ayuntamiento } \\
\end{array}$ & \\
\hline 1648 & 38.071 & Legajo & Pleito judicial & Pleito por la ejecución de un censo & Logroño & $\begin{array}{l}\text { Consejo de Hacienda } \\
\text { Compañia de Jesús }\end{array}$ & Gaspar de Jao \\
\hline 1648 & 28.041 & Legajo & Pleito judicial & $\begin{array}{l}\text { Excomunión del alcalde mayor por procesar } \\
\text { y ejecutar a un asesino penitenciado del } \\
\text { Santo Oficio }\end{array}$ & Logroño & $\begin{array}{l}\text { Inquisición } \\
\text { Consejo de Castilla }\end{array}$ & $\begin{array}{l}\text { Juan Cochet } \\
\text { (penitenciado del } \\
\text { Santo Oficio) }\end{array}$ \\
\hline 1649 & 25.641 & Legajo & Pleito judicial & $\begin{array}{l}\text { Provisión de un beneficio en la parroquia de } \\
\text { Santiago }\end{array}$ & Logroño & $\begin{array}{l}\text { Iglesia de Santiago } \\
\text { Consejo de Castilla }\end{array}$ & $\begin{array}{l}\text { Francisco Ortiz Uriarte } \\
\text { (clérigo) }\end{array}$ \\
\hline 1649 & 25.641 & Legajo & $\begin{array}{l}\text { Juicio de } \\
\text { comisión }\end{array}$ & $\begin{array}{l}\text { Motin contra varios vecinos que pretendian } \\
\text { perpetuar los oficios de regidores }\end{array}$ & $\begin{array}{l}\text { Torrecilla de } \\
\text { Cameros } \\
\end{array}$ & $\begin{array}{l}\text { Consejo de Castilla } \\
\text { Ayuntamiento }\end{array}$ & \\
\hline 1650 & 25.665 & Legajo & Pleito judicial & $\begin{array}{l}\text { El Ayuntamiento se niega a reconocer a un } \\
\text { juez de comisión por no haber fijado su } \\
\text { audiencia en la ciudad. }\end{array}$ & $\begin{array}{l}\text { Santo } \\
\text { Domingo de } \\
\text { la Calzada }\end{array}$ & $\begin{array}{l}\text { Ayuntamiento } \\
\text { Consejo de Castilla }\end{array}$ & \\
\hline 1651 & 25.783 & Legajo & Pleito judicial & $\begin{array}{l}\text { El diputado del común solicita se inhabilite } \\
\text { a los regidores para participar en la elección } \\
\text { de su cargo. }\end{array}$ & Calahorra & $\begin{array}{l}\text { Consejo de Castilla } \\
\text { Ayuntamiento }\end{array}$ & $\begin{array}{l}\text { Juan Navarro } \\
\text { (Diputado del común) }\end{array}$ \\
\hline 1651 & 32.919 & Legajo & Pleito judicial & $\begin{array}{l}\text { Consumo de los oficios de regidores } \\
\text { perpetuos }\end{array}$ & $\begin{array}{l}\text { Torrecilla de } \\
\text { Cameros }\end{array}$ & $\begin{array}{l}\text { Ayuntamiento } \\
\text { Consejo de Castilla }\end{array}$ & \\
\hline 1652 & 25.750 & Legajo & Pleito judicial & $\begin{array}{l}\text { Consumo de los regimientos perpetuos de } \\
\text { la ciudad por los vecinos del común y el } \\
\text { clero. }\end{array}$ & Calahorra & $\begin{array}{l}\text { Consejo de Castilla } \\
\text { Ayuntamiento } \\
\text { Obispado }\end{array}$ & \\
\hline 1652 & 25.600 & Legajo & Pleito judicial & Elección de procurador del común & Logroño & $\begin{array}{l}\text { Ayuntamiento } \\
\text { Consejo de Castilla }\end{array}$ & \\
\hline 1652 & 25.663 & Legajo & $\begin{array}{l}\text { Juicio de } \\
\text { comisión }\end{array}$ & $\begin{array}{l}\text { Consumo de los oficios de regidores } \\
\text { perpetuos. concejo abierto. }\end{array}$ & Alfaro & $\begin{array}{l}\text { Consejo de Castilla } \\
\text { Ayuntamiento }\end{array}$ & $\begin{array}{l}\text { Ldo. Esteban de } \\
\text { Meneses (alcalde } \\
\text { mayor) }\end{array}$ \\
\hline 1652 & 25.599 & Legajo & Pleito judicial & $\begin{array}{l}\text { Intento de prohibir los concejos abiertos. } \\
\text { Elección del procurador general del común. }\end{array}$ & Alfaro & $\begin{array}{l}\text { Consejo de Castilla } \\
\text { Ayuntamiento }\end{array}$ & $\begin{array}{l}\text { Ldo. Esteban de } \\
\text { Meneses (aicalde } \\
\text { mayor) }\end{array}$ \\
\hline 1652 & 25.694 & Legajo & Pleito judicial & $\begin{array}{l}\text { Motín antiseñorial. Negativa de los vecinos } \\
\text { a aceptar como señor al heredero del } \\
\text { duque de Nájera. }\end{array}$ & Navarrete & $\begin{array}{l}\text { Consejo de Castilla } \\
\text { Ayuntamiento }\end{array}$ & $\begin{array}{l}\text { Jaime Manuel } \\
\text { Monserrate (duque de } \\
\text { Nájera) } \\
\text { Francisco Maria } \\
\text { Monserrate (duque de } \\
\text { Nájera) }\end{array}$ \\
\hline 1652 & 25.694 & Legajo & $\begin{array}{l}\text { Juicio de } \\
\text { comisión }\end{array}$ & $\begin{array}{l}\text { Motín antiseñorial tras negarse a reconocer } \\
\text { como señor al nuevo duque de Nájera. }\end{array}$ & Nájera & $\begin{array}{l}\text { Consejo de Castilla } \\
\text { Ayuntamiento }\end{array}$ & $\begin{array}{l}\text { Jaime Manuel de } \\
\text { Cárdenas Manrique de } \\
\text { Lara (duque de Nájera) } \\
\end{array}$ \\
\hline 1653 & 25.665 & Legajo & $\begin{array}{l}\text { Juicio de } \\
\text { Comisión }\end{array}$ & Proceso por resello de moneda & Arnedo & Consejo de Castilla & \\
\hline
\end{tabular}




\begin{tabular}{|c|c|c|c|c|c|c|c|}
\hline 1653 & 25.599 & Legajo & $\begin{array}{l}\text { Juicio de } \\
\text { comisión }\end{array}$ & $\begin{array}{l}\text { Injurias y agresiones a varias mujeres. } \\
\text { Lucha de bandos entre nobleza. }\end{array}$ & Navarrete & Consejo de Castilla & \\
\hline 1653 & 7.153 & Legajo & $\begin{array}{l}\text { Consulta de } \\
\text { gracia y } \\
\text { justicia }\end{array}$ & $\begin{array}{l}\text { El Consejo de Castilla informa al rey de los } \\
\text { tumultos populares de Alfaro. }\end{array}$ & Alfaro & Consejo de Castilla & \\
\hline 1653 & 2.769 & Libro & Asiento & $\begin{array}{l}\text { Consulta del Consejo al rey sobre los } \\
\text { tumultos de Alfaro }\end{array}$ & Alfaro & Consejo de Castilla & \\
\hline 1653 & 25.764 & Legajo & Pleito judicial & $\begin{array}{l}\text { Disputa sobre la titularidad de la jurisdicción } \\
\text { sobre las alcabalas entre las autoridades } \\
\text { judiciales señoriales y municipales. }\end{array}$ & Navarrete & $\begin{array}{l}\text { Consejo de Hacienda } \\
\text { Ayuntamiento }\end{array}$ & $\begin{array}{l}\text { Inés María de Arellano } \\
\text { (tutora de Francisco } \\
\text { Maria Monserrate, } \\
\text { duque de Nájera) }\end{array}$ \\
\hline 1653 & 27.960 & Legajo & Pleito judicial & $\begin{array}{l}\text { Compra de las alcabalas de la ciudad por el } \\
\text { duque de Nájera. }\end{array}$ & Nájera & $\begin{array}{l}\text { Consejo de Hacienda } \\
\text { Ayuntamiento }\end{array}$ & $\begin{array}{l}\text { Francisco Maria } \\
\text { Monserrate (duque de } \\
\text { Nájera) } \\
\end{array}$ \\
\hline 1653 & 27.962 & Legajo & Pleito judicial & $\begin{array}{l}\text { Los regidores exigen que el alcalde mayor } \\
\text { del duque de Nájera sea sometido a juicio } \\
\text { de residencia. }\end{array}$ & Nájera & $\begin{array}{l}\text { Consejo de Castilla } \\
\text { Ayuntamiento }\end{array}$ & $\begin{array}{l}\text { Duque de Nájera } \\
\text { Ldo. Francisco } \\
\text { Valdivieso Olavarria } \\
\text { (alcalde mayor) }\end{array}$ \\
\hline 1653 & 7.163 & Legajo & $\begin{array}{l}\text { Juicio de } \\
\text { comisión } \\
\end{array}$ & $\begin{array}{l}\text { Alborotos populares tras saberse la } \\
\text { perpetuación de los oficios de regidores. }\end{array}$ & Alfaro & $\begin{array}{l}\text { Consejo de Castilla } \\
\text { Ayuntamiento }\end{array}$ & \\
\hline 1654 & 50.992 & Legajo & $\begin{array}{l}\text { Visita de } \\
\text { escribanos }\end{array}$ & $\begin{array}{l}\text { Procesamiento de Lorenzo Castellanos, } \\
\text { escribano del número. }\end{array}$ & Logroño & Consejo de Castilla & $\begin{array}{l}\text { Lorenzo Castellanos } \\
\text { (escribano del número) } \\
\text { Francisco de Paz (juez } \\
\text { visitador) } \\
\end{array}$ \\
\hline 1654 & 27.982 & Legajo & Pleito judicial & $\begin{array}{l}\text { Negativa del concejo a reconocer al alcalde } \\
\text { mayor }\end{array}$ & Logroño & $\begin{array}{l}\text { Consejo de Castilla } \\
\text { Ayuntamiento } \\
\end{array}$ & $\begin{array}{l}\text { Esteban de Meneses } \\
\text { (alcalde mayor) }\end{array}$ \\
\hline 1654 & 27.960 & Legajo & Pleito judicial & $\begin{array}{l}\text { Malos tratos contra los alguaciles de la } \\
\text { duquesa de Néjera. }\end{array}$ & Navarrete & $\begin{array}{l}\text { Consejo de Castilla } \\
\text { Ayuntamiento }\end{array}$ & $\begin{array}{l}\text { Duquesa de Najera } \\
\text { Francisco Valdivieso } \\
\text { (gobernador de la } \\
\text { duquesa) } \\
\text { Diego Pèrez (alcalde } \\
\text { ordinario) } \\
\end{array}$ \\
\hline 1654 & 41.412 & Legajo & Pleito judicial & $\begin{array}{l}\text { Facultad para construir una presa en el } \\
\text { Ebro (Campo Murillo) a costa de los } \\
\text { regantes. }\end{array}$ & Calahorra & $\begin{array}{l}\text { Consejo de Hacienda } \\
\text { Ayuntamiento }\end{array}$ & \\
\hline 1654 & 42.600 & Legajo & \begin{tabular}{|l} 
Visita de \\
escribanos
\end{tabular} & Inspección de las escribanias & Logroño & Consejo de Castilla & \\
\hline 1654 & 41.413 & Legajo & $\begin{array}{l}\text { Juicio de } \\
\text { residencia }\end{array}$ & Residencia al alcalde mayor de Calahorra & Calahorra & $\begin{array}{l}\text { Consejo de Castilla } \\
\text { Ayuntamiento }\end{array}$ & \\
\hline 1654 & 28.067 & Legajo & $\begin{array}{l}\text { Juicio de } \\
\text { residencia }\end{array}$ & Residencia a los oficiales del concejo & Navarrete & $\begin{array}{l}\text { Consejo de Castilla } \\
\text { Ayuntamiento }\end{array}$ & \\
\hline
\end{tabular}




\begin{tabular}{|c|c|c|c|c|c|c|c|}
\hline 1655 & 25.689 & Legajo & Pleito judicial & $\begin{array}{l}\text { Denunica de varios regidores hidalgos } \\
\text { contra el corregidor }\end{array}$ & Logroño & $\begin{array}{l}\text { Consejo de Castilla } \\
\text { Ayuntamiento }\end{array}$ & $\begin{array}{l}\text { Alonso Sarmiento } \\
\text { (corregidor y oidor de } \\
\text { la Chancillería de } \\
\text { Valladolid) }\end{array}$ \\
\hline 1655 & 25.607 & Legajo & Pleito judicial & $\begin{array}{l}\text { Denuncia contra el corregidor por apresar a } \\
\text { su alcalde mayor estando en sagrado }\end{array}$ & Logroño & $\begin{array}{l}\text { Obispado de Calahorra } \\
\text { Iglesia de Santiago } \\
\text { Consejo de Castilla }\end{array}$ & $\begin{array}{l}\text { Alonso Sarmiento } \\
\text { (corregidor) } \\
\text { Juan González de Lara } \\
\text { (alcalde mayor) }\end{array}$ \\
\hline 1655 & 25.689 & Legajo & Pleito judicial & Elección de procurador mayor & Logroño & $\begin{array}{l}\text { Ayuntamiento } \\
\text { Consejo de Castilla }\end{array}$ & $\begin{array}{l}\text { Juan Bautista Sáenz } \\
\text { de Aguirre (procurador } \\
\text { mayor) }\end{array}$ \\
\hline 1655 & 25.712 & Legajo & Pleito judicial & Asesinato en el balneario de Arnedillo. & $\begin{array}{l}\text { Fuenmayor } \\
\text { Medrano } \\
\text { Arnedillo }\end{array}$ & Consejo de Castilla & $\begin{array}{l}\text { Melchor Grijalba } \\
\text { Pedro Campilio }\end{array}$ \\
\hline 1655 & 30.378 & Legajo & $\begin{array}{l}\text { Juicio de } \\
\text { residencia }\end{array}$ & $\begin{array}{l}\text { Denuncias de un regidor perpetuo contra el } \\
\text { alcalde mayor }\end{array}$ & Alfaro & $\begin{array}{l}\text { Consejo de Castilla } \\
\text { Ayuntamiento }\end{array}$ & $\begin{array}{l}\text { Garcia Vallés (regidor } \\
\text { perpetuo) } \\
\text { Esteban de Meneses } \\
\text { (alcalde mayor) } \\
\text { Pedro Larrinque (juez } \\
\text { de residencia) }\end{array}$ \\
\hline 1656 & 25.661 & Legajo & Pleito judicial & $\begin{array}{l}\text { Amenazas de los vecinos a los oficiales } \\
\text { señoriales }\end{array}$ & Fuenmayor & Consejo de Castilla & $\begin{array}{l}\text { Gaspara Vélez de } \\
\text { Medrano (marquesa } \\
\text { de La Lapilla) }\end{array}$ \\
\hline 1656 & 25.696 & Legajo & Pleito judicial & $\begin{array}{l}\text { Denuncia de los regidores contra el alcalde } \\
\text { mayor por haber entregado una fianza } \\
\text { ilegal. }\end{array}$ & Calahorra & $\begin{array}{l}\text { Ayuntamiento } \\
\text { Chancilleria de Valladolid } \\
\text { Consejo de Castilla }\end{array}$ & $\begin{array}{l}\text { Ldo. Andrés del } \\
\text { Castillo (alcalde } \\
\text { mayor) }\end{array}$ \\
\hline 1656 & 24.694 & Legajo & Pleito judicial & $\begin{array}{l}\text { Negativa de la villa a admitir como señora a } \\
\text { la marquesa de Cañete, heredera del duque } \\
\text { de Nájera. }\end{array}$ & Cenicero & $\begin{array}{l}\text { Consejo de Castilla } \\
\text { Ayuntamiento }\end{array}$ & $\begin{array}{l}\text { Francisco Maria } \\
\text { Monserrate (duque de } \\
\text { Nájera) } \\
\text { Marquesa de Cañete }\end{array}$ \\
\hline 1656 & 25.630 & Legajo & Pleito judicial & $\begin{array}{l}\text { El padre y el marido de una mujer la } \\
\text { asesinan por sospechas de adulterio }\end{array}$ & Navarrete & $\begin{array}{l}\text { Inquisición } \\
\text { Consejo de Castilla }\end{array}$ & Francisca Revollo \\
\hline 1656 & 28.037 & Legajo & Pleito judicial & Pleito entre eclesiásticos & Arenzana & Consejo de Castilla & \\
\hline 1657 & 7.167 & Legajo & $\begin{array}{l}\text { Consulta de } \\
\text { gracia y } \\
\text { justicia } \\
\end{array}$ & $\begin{array}{l}\text { El Consejo de Castilla aconseja al rey } \\
\text { aceptar el deseo del conde de Aguilar de } \\
\text { entrevistarse con él. }\end{array}$ & Cameros & Consejo de Castilla & Conde de Aguilar \\
\hline 1657 & 33.975 & Legajo & Pleito judicial & $\begin{array}{l}\text { Denuncia del Condestable contra los } \\
\text { vecinos por negarse a admitir a su } \\
\text { administrador de alcabalas }\end{array}$ & Arnedo & $\begin{array}{l}\text { Consejo de Hacienda } \\
\text { Ayuntamiento }\end{array}$ & $\begin{array}{l}\text { Iñigo Melchor de } \\
\text { Velasco y Tovar } \\
\text { (Condestable de } \\
\text { Castilia) } \\
\end{array}$ \\
\hline
\end{tabular}




\begin{tabular}{|c|c|c|c|c|c|c|c|}
\hline 1657 & 25.906 & Legajo & Pleito judicial & $\begin{array}{l}\text { Concurso de acreedores contra los Propios } \\
\text { de la ciudad }\end{array}$ & Logroño & $\begin{array}{l}\text { Consejo de Castilla } \\
\text { Chancilleria de Valladolid } \\
\text { Ayuntamiento }\end{array}$ & $\begin{array}{l}\text { Alonso de los Rios } \\
\text { Angulo (corregidor) }\end{array}$ \\
\hline 1657 & 25.742 & Legajo & Pleito judicial & $\begin{array}{l}\text { Negativa de los vecinos a admitir al alcalde } \\
\text { mayor nombrado por la duquesa. }\end{array}$ & Navarrete & $\begin{array}{l}\text { Consejo de Castilla } \\
\text { Ayuntamiento }\end{array}$ & Duquesa de Nájera \\
\hline 1657 & $\begin{array}{l}13.208 \\
\exp . n^{\circ} 82 \\
\end{array}$ & Legajo & $\begin{array}{l}\text { Decreto de } \\
\text { gracia }\end{array}$ & $\begin{array}{l}\text { Confirmación al conde de Castilforido de la } \\
\text { alcaidia de Logroño }\end{array}$ & Logroño & Consejo de Castilla & Conde de Castilflorido \\
\hline 1658 & 33.975 & Legajo & Pleito judicial & $\begin{array}{l}\text { Pleito antiseñorial por el pago de las } \\
\text { alcabalas de la villa, propiedad del señor. }\end{array}$ & Arnedo & $\begin{array}{l}\text { Consejo de Hacienda } \\
\text { Ayuntamiento }\end{array}$ & $\begin{array}{l}\text { Condestable de } \\
\text { Castilla }\end{array}$ \\
\hline 1658 & 38.097 & Legajo & Pleito judicial & Pleito por la ejecución de un juro & Logroño & $\begin{array}{l}\text { Consejo de Hacienda } \\
\text { Ayuntamiento }\end{array}$ & \\
\hline 1658 & 25.708 & Legajo & $\begin{array}{l}\text { Juicio de } \\
\text { comisión }\end{array}$ & $\begin{array}{l}\text { Procesamiento de los regidores por fraudes } \\
\text { en la administración de los Propios y los } \\
\text { Arbitrios }\end{array}$ & Calahorra & $\begin{array}{l}\text { Consejo de Castilla } \\
\text { Ayuntamiento }\end{array}$ & $\begin{array}{l}\text { Ldo. Domingo } \\
\text { González Andosilla } \\
\text { (juez de comisión) }\end{array}$ \\
\hline 1658 & 25.757 & Legajo & $\begin{array}{l}\text { Concordia } \\
\text { Informe }\end{array}$ & Perpetuación de los regimientos & Logroño & $\begin{array}{l}\text { Consejo de Castilla } \\
\text { Ayuntamiento }\end{array}$ & \\
\hline 1658 & 36.648 & Legajo & $\begin{array}{l}\text { Acta de } \\
\text { ejecución de } \\
\text { una concordia }\end{array}$ & Perpetuación de los oficios de regidores. & Logroño & $\begin{array}{l}\text { Consejo de Castilla } \\
\text { Ayuntamiento }\end{array}$ & \\
\hline 1658 & 25.757 & Legajo & $\begin{array}{l}\text { Acta de } \\
\text { ejecución de } \\
\text { Provisión Real }\end{array}$ & Perpetuación de los oficios de regidores. & Logroño & $\begin{array}{l}\text { Consejo de Castilla } \\
\text { Ayuntamiento }\end{array}$ & \\
\hline 1658 & 25.926 & Legajo & Pleito judicial & $\begin{array}{l}\text { Denuncia de la marquesa de la Lapilla } \\
\text { contra los vecinos por no reconocer sus } \\
\text { derechos jurisdiccionales. }\end{array}$ & $\begin{array}{l}\text { Fuenmayor } \\
\text { Navarrete }\end{array}$ & Consejo de Castilla & $\begin{array}{l}\text { Gaspara Vélez de } \\
\text { Medrano (marquesa } \\
\text { de la Lapilla) }\end{array}$ \\
\hline 1658 & 27.917 & Legajo & $\begin{array}{l}\text { informe y } \\
\text { memorial }\end{array}$ & $\begin{array}{l}\text { Reparación del puente y las presas del } \\
\text { Alhama }\end{array}$ & Alfaro & $\begin{array}{l}\text { Consejo de Castilla } \\
\text { Ayuntamiento }\end{array}$ & \\
\hline 1658 & 25.712 & Legajo & Pleito judicial & $\begin{array}{l}\text { Disputa sobre el Primer asiento de la } \\
\text { Cuadrilla de León }\end{array}$ & Brieva & $\begin{array}{l}\text { Consejo de Castilla } \\
\text { Concejo de la Mesta } \\
\text { Cuadrilla de León }\end{array}$ & $\begin{array}{l}\text { José Garcia Ulloa } \\
\text { Pedro de Neila (señor } \\
\text { de Quintanar) } \\
\end{array}$ \\
\hline 1659 & 25.719 & Legajo & Pleito judicial & Retención de bulas & Logroño & Consejo de Castilla & $\begin{array}{l}\text { Melchor Ponce de } \\
\text { León (clérigo) }\end{array}$ \\
\hline 1659 & 25.719 & Legajo & Pleito judicial & $\begin{array}{l}\text { Provisión de una canongia en contra de los } \\
\text { privilegios de los parroquianos }\end{array}$ & Logroño & $\begin{array}{l}\text { Iglesia de Santa Maria de } \\
\text { la Redonda } \\
\text { Patronato Real } \\
\text { Consejo de Castilla }\end{array}$ & \\
\hline 1659 & 25.665 & Legajo & $\begin{array}{l}\text { Juicio de } \\
\text { comisión }\end{array}$ & Falsificación de moneda de vellón. & $\begin{array}{l}\text { Arnedo } \\
\text { Autol } \\
\text { Arnedillo } \\
\text { Préjano } \\
\text { Calahorra } \\
\end{array}$ & Consejo de Castilla & \\
\hline
\end{tabular}




\begin{tabular}{|c|c|c|c|c|c|c|c|}
\hline 1660 & 25.716 & Legajo & Pleito judicial & $\begin{array}{l}\text { Consumo del oficio de alguacil mayor } \\
\text { perpetuo por los vecinos }\end{array}$ & Calahorra & $\begin{array}{l}\text { Consejo de Castilla } \\
\text { Ayuntamiento }\end{array}$ & $\begin{array}{l}\text { Francisco Cartagena } \\
\text { (alguacil mayor de } \\
\text { Calahorra y escribano } \\
\text { del número de Madrid) }\end{array}$ \\
\hline 1660 & 25.812 & Legajo & $\begin{array}{l}\text { Memorial y } \\
\text { Acta de } \\
\text { concejo } \\
\text { abierto }\end{array}$ & $\begin{array}{l}\text { Concejo abierto para recaudar fondos con } \\
\text { los que pleitear contra la señora de la villa. }\end{array}$ & Fuenmayor & Consejo de Castilla & $\begin{array}{l}\text { Gaspara Vélez de } \\
\text { Medrano (marquesa } \\
\text { de la Lapilla) }\end{array}$ \\
\hline 1660 & 38.101 & Legajo & Pleito judicial & $\begin{array}{l}\text { Fraudes de los vecinos en las alcabalas } \\
\text { que pagan al duque }\end{array}$ & \begin{tabular}{|l|} 
Villoslada de \\
Cameros \\
\end{tabular} & $\begin{array}{l}\text { Consejo de Castilla } \\
\text { Ducado de Nájera } \\
\end{array}$ & Duque de Nájera \\
\hline 1661 & 27.853 & Legajo & $\begin{array}{l}\text { Juicio de } \\
\text { comisión }\end{array}$ & Contrabando de plata & Calahorra & Consejo de Hacienda & \\
\hline 1662 & 28.163 & Legajo & Pleito judicial & Construcción de la Iglesia Colegial & Alfaro & $\begin{array}{l}\text { Consejo de Castilla } \\
\text { Catedral de Tarazona } \\
\text { Iglesia Colegial } \\
\text { Ayuntamiento } \\
\end{array}$ & \\
\hline 1662 & 7.172 & Legajo & Petición & $\begin{array}{l}\text { Petición de la villa en el pleito sobre el } \\
\text { reparto del agua del Alhama }\end{array}$ & $\begin{array}{l}\text { Cervera del } \\
\text { rio Alhama }\end{array}$ & $\begin{array}{l}\text { Consejo de Castilla } \\
\text { Ayuntamiento }\end{array}$ & \\
\hline 1663 & 25.757 & Legajo & Pleito judicial & Preeminencia de los regidores & Logroño & $\begin{array}{l}\text { Consejo de Castilla } \\
\text { Ayuntamiento }\end{array}$ & Diego Orive (regidor) \\
\hline 1663 & 25.759 & Legajo & Pleito judicial & $\begin{array}{l}\text { Pletio entre eclesiásticos regulares sobre } \\
\text { bulas }\end{array}$ & Logroño & $\begin{array}{l}\text { Convento de los } \\
\text { Capuchinos (Laguardia, } \\
\text { Alava) } \\
\text { Convento de los } \\
\text { Observantes (Logroño) } \\
\text { Consejo de Castilla } \\
\end{array}$ & \\
\hline 1663 & 33.987 & Legajo & $\begin{array}{l}\text { Juicio de } \\
\text { comisión }\end{array}$ & Motín antiseñorial tras ser vendida la aldea. & $\begin{array}{l}\text { Aldeanueva } \\
\text { de Ebro }\end{array}$ & $\begin{array}{l}\text { Consejo de Castilla } \\
\text { Consejo de Hacienda }\end{array}$ & $\begin{array}{l}\text { Juan Manuel lñiguez } \\
\text { de Arnedo (Oidor del } \\
\text { Consejo de Hacienda y } \\
\text { Señor de Aldeanueva) }\end{array}$ \\
\hline 1663 & 25.757 & Legajo & Pleito judicial & $\begin{array}{l}\text { Negativa del Ayuntamiento a admitir a un } \\
\text { nuevo regidor perpetuo. }\end{array}$ & Logroño & $\begin{array}{l}\text { Ayuntamiento } \\
\text { Consejo de Castilla }\end{array}$ & $\begin{array}{l}\text { Diego Orive Vergara } \\
\text { (regidor perpetuo) } \\
\text { Diego Orive Alonso } \\
\text { (regidor perpetuo) }\end{array}$ \\
\hline 1663 & 34.017 & Legajo & $\begin{array}{l}\text { Juicio de } \\
\text { comisión }\end{array}$ & Sentencias del motín antiseñorial & $\begin{array}{l}\text { Aldeanueva } \\
\text { de Ebro }\end{array}$ & Consejo de Castilla & $\begin{array}{l}\text { Juan Ruiz Fernández } \\
\text { (alcalde mayor de } \\
\text { Alfaro y Juez de } \\
\text { Comisión) } \\
\end{array}$ \\
\hline 1664 & 38.138 & Legajo & $\begin{array}{l}\text { Juicio de } \\
\text { comisión }\end{array}$ & $\begin{array}{l}\text { Compra por la villa de la jurisdicción de } \\
\text { tolerancia que posee su señor }\end{array}$ & $\begin{array}{l}\text { Leza de Rio } \\
\text { Leza }\end{array}$ & Consejo de Castilla & $\begin{array}{l}\text { Juan Guerrero } \\
\text { Contreras (Señor de } \\
\text { Leza) }\end{array}$ \\
\hline
\end{tabular}




\begin{tabular}{|c|c|c|c|c|c|c|c|}
\hline 1664 & 32.871 & Legajo & Pleito judicial & $\begin{array}{l}\text { Quejas de los hidalgos por negarse los } \\
\text { pecheros a respetar sus privilegios }\end{array}$ & Arnedo & Consejo de Castilla & \\
\hline 1664 & 25.783 & Legajo & Pleito judicial & $\begin{array}{l}\text { El ayuntamiento denuncia al Recibidor de } \\
\text { Milones por no establecer su Audiencia en } \\
\text { la ciudad }\end{array}$ & $\begin{array}{l}\text { Santo } \\
\text { Domingo de } \\
\text { la Calzada } \\
\text { Arenzana } \\
\end{array}$ & $\begin{array}{l}\text { Consejo de Castilla } \\
\text { Ayuntamiento } \\
\text { Adelantamiento de } \\
\text { Arenzana }\end{array}$ & \\
\hline 1664 & 42.624 & Legajo & $\begin{array}{l}\text { Visita de } \\
\text { escribanos }\end{array}$ & Inspección de las escribanias & Logroño & Consejo de Castilla & \\
\hline 1664 & 28.425 & Legajo & Pleito judicial & Consumo de un oficio de escribano & Ventrosa & $\begin{array}{l}\text { Consejo de Castitla } \\
\text { Ayuntamiento }\end{array}$ & \\
\hline 1665 & 7.175 & Legajo & $\begin{array}{l}\text { Informes y } \\
\text { autos }\end{array}$ & $\begin{array}{l}\text { Correspondencia entre el corregidor de } \\
\text { Logroño, el regente de Navarra y el } \\
\text { Consejo sobre el envio de aquellos como } \\
\text { jueces pesquisidores contra los vecinos } \\
\text { amotinados de Calahorra. }\end{array}$ & $\begin{array}{l}\text { Calahorra } \\
\text { Arnedo } \\
\text { Logroño } \\
\text { Alfaro } \\
\text { Navarra } \\
\text { Agreda }\end{array}$ & $\begin{array}{l}\text { Consejo de Castilla } \\
\text { Corregimiento de Logroño } \\
\text { Reino de Navarra } \\
\text { Obispado de Calahorra }\end{array}$ & $\begin{array}{l}\text { Alonso de Llanes y } \\
\text { Valdés (Regente de } \\
\text { Navarra) }\end{array}$ \\
\hline 1665 & $\begin{array}{l}13.250 \\
(\text { Exp.73) }\end{array}$ & Legajo & $\begin{array}{l}\text { Petición de } \\
\text { gracia }\end{array}$ & $\begin{array}{l}\text { Cinco mujeres de Calahorra piden a la reina } \\
\text { el indulto para sus maridos, condenados } \\
\text { por el motín de Calahorra }\end{array}$ & Calahorra & $\begin{array}{l}\text { Consejo de Castilla } \\
\text { Regencia del reino }\end{array}$ & $\begin{array}{l}\text { Mariana de Austria } \\
\text { (regenta) }\end{array}$ \\
\hline 1665 & 25.817 & Legajo & $\begin{array}{l}\text { Juicio de } \\
\text { comisión }\end{array}$ & $\begin{array}{l}\text { Sumario de la pesquisa contra los vecinos } \\
\text { amotinados en Calahorra }\end{array}$ & Calahorra & Consejo de Castilla & $\begin{array}{l}\text { Alonso de Llanes y } \\
\text { Valdés (juez } \\
\text { pesquisidor, regente } \\
\text { de Navarra) }\end{array}$ \\
\hline 1665 & $\begin{array}{l}13.250 \\
\text { Exp. } 74\end{array}$ & Legajo & \begin{tabular}{|l|} 
Real Decreto \\
\end{tabular} & $\begin{array}{l}\text { Orden de la regente al Consejo para que } \\
\text { dicte indulto contra los vecinos condenados } \\
\text { en el motin de Calahorra, excepto los } 6 \text { con } \\
\text { mayor culpa. }\end{array}$ & Calahorra & $\begin{array}{l}\text { Consejo de Castilla } \\
\text { Cámara de Castilla }\end{array}$ & $\begin{array}{l}\text { Mariana de Austria } \\
\text { (regente) }\end{array}$ \\
\hline 1665 & 27.921 & Legajo & Pleito judicial & $\begin{array}{l}\text { Acrecentamiento de los regimientos } \\
\text { perpetuos }\end{array}$ & Alfaro & $\begin{array}{l}\text { Consejo de Castilla } \\
\text { Ayuntamiento }\end{array}$ & \\
\hline 1665 & 23.815 & Legajo & Pleito judicial & $\begin{array}{l}\text { Disputas por la fundación en la ciudad de } \\
\text { un convento de Trinitarios }\end{array}$ & Alfaro & Consejo de Castilla & \\
\hline 1666 & 33.994 & Legajo & Pleito judicial & Fraude en las alcabalas de la ciudad & $\begin{array}{l}\text { Santo } \\
\text { Domingo de } \\
\text { la Calzada }\end{array}$ & Consejo de Hacienda & \\
\hline$\overline{1666}$ & 25.075 & Legajo & Pleito judicial & $\begin{array}{l}\text { Pleito entre tres nobles por la tenuta del } \\
\text { ducado de Najera }\end{array}$ & Nájera & $\begin{array}{l}\text { Consejo de Castilla } \\
\text { Ducado de Nájera }\end{array}$ & \\
\hline 1666 & 7.176 & Legajo & Petición & $\begin{array}{l}\text { Petición de la villa para que se agilice la } \\
\text { tramitación del pleito contra el duque de } \\
\text { Nájera }\end{array}$ & Nájera & $\begin{array}{l}\text { Consejo de Castilla } \\
\text { Ayuntamiento }\end{array}$ & \\
\hline 1666 & 25.829 & Legajo & Pleito judicial & $\begin{array}{l}\text { Disputa por la jurisdicción de la villa entre el } \\
\text { conde de Castelfuerte y el marqués de } \\
\text { Almazán }\end{array}$ & Cornago & Consejo de Castilla & $\begin{array}{l}\text { Conde de Castilfuertes } \\
\text { Marqués de Almazán }\end{array}$ \\
\hline
\end{tabular}




\begin{tabular}{|c|c|c|c|c|c|c|c|}
\hline 1667 & 23.837 & Legajo & Pleito judicial & Aprobación de las ordenanzas de la villa. & Albelda & $\begin{array}{l}\text { Consejo de Castilla } \\
\text { Ayuntamiento }\end{array}$ & \\
\hline 1667 & 28.426 & Legajo & Pleito judicial & Aprobación de las ordenanzas de la villa & Arenzana & $\begin{array}{l}\text { Consejo de Castilla } \\
\text { Ayuntamiento }\end{array}$ & \\
\hline 1668 & 25.896 & Legajo & Informes & $\begin{array}{l}\text { Conflictos en la ciudad por el rumor de que } \\
\text { se iban a reinstaurar el pago de los } \\
\text { impuestos mediante repartimiento entre los } \\
\text { vecinos. }\end{array}$ & Calahorra & $\begin{array}{l}\text { Consejo de Castilla } \\
\text { Ayuntamiento }\end{array}$ & $\begin{array}{l}\text { Andrés de Sandi } \\
\text { (regidor) } \\
\text { José Cabriada } \\
\text { (regidor) } \\
\text { Antonio Fuenmayor } \\
\text { (regidor) } \\
\text { Manuel Mancebo de } \\
\text { Velasco (regidor) }\end{array}$ \\
\hline 1668 & 25.863 & Legajo & $\begin{array}{l}\text { Juicio de } \\
\text { residencia }\end{array}$ & Juicio de residencia al corregidor & Logroño & $\begin{array}{l}\text { Corregimiento } \\
\text { Consejo de Castilla }\end{array}$ & $\begin{array}{l}\text { Pedro Lerras } \\
\text { (corregidor) } \\
\text { Francisco Paquier } \\
\text { (corregidor) }\end{array}$ \\
\hline 1668 & 28.247 & Legajo & Pleito judicial & $\begin{array}{l}\text { Los pecheros denuncian a los hidalgos por } \\
\text { negarse a contribuir en los gastos de las } \\
\text { levas de soldados. }\end{array}$ & Igea & Consejo de Castilla & \\
\hline 1668 & 28.427 & Legajo & Pleito judicial & $\begin{array}{l}\text { Los vecinos pecheros denuncian a los } \\
\text { hidalgos por negarse a contribuir en los } \\
\text { gastos de las levas de soldados. }\end{array}$ & Cornago & Consejo de Castila & \\
\hline 1668 & 28.163 & Legajo & Pleito judicial & $\begin{array}{l}\text { Embargo de diezmos de la iglesia de } \\
\text { Palacio por las autoridades de Fuenmayor }\end{array}$ & $\begin{array}{l}\text { Logroño } \\
\text { Fuenmayor }\end{array}$ & $\begin{array}{l}\text { Iglesia de Santa Maria de } \\
\text { Palacio } \\
\text { Consejo de Castilla }\end{array}$ & \\
\hline 1668 & 28.323 & Legajo & Pleito judicial & Pleito sobre el cumplimiento de un privilegio & Ezcaray & $\begin{array}{l}\text { Consejo de Castilla } \\
\text { Ayuntamiento }\end{array}$ & \\
\hline 1668 & 25.856 & Legajo & $\begin{array}{l}\text { Juicio de } \\
\text { comisión }\end{array}$ & Faisificación de moneda de vellón & Arnedo & Consejo de Hacienda & \\
\hline 1669 & 34.002 & Legajo & Pleito judicial & Proceso por deudas contra un mercader & Logroño & Consejo de Hacienda & $\begin{array}{l}\text { Diego Antonio } \\
\text { Menaute (mercader) }\end{array}$ \\
\hline 1669 & 25.897 & Legajo & Pleito judicial & $\begin{array}{l}\text { Consumo de los oficios de regidores } \\
\text { perpetuos. }\end{array}$ & Fuenmayor & Consejo de Hacienda & \\
\hline 1669 & 27.701 & Legajo & Pleito judicial & $\begin{array}{l}\text { El duque de Nájera contra los privilegios de } \\
\text { los herederos de Antoña Garcia. }\end{array}$ & Cenicero & Consejo de Castilla & \\
\hline 1669 & 25.861 & Legajo & Pleito judicial & $\begin{array}{l}\text { Pleito contra el concejo por la paga de un } \\
\text { censo }\end{array}$ & Calahorra & $\begin{array}{l}\text { Consejo de Castilla } \\
\text { Ayuntamiento }\end{array}$ & \\
\hline 1669 & 25.881 & Legajo & Pleito judicial & $\begin{array}{l}\text { Aprobación por el Consejo de las } \\
\text { ordenanzas de la villa }\end{array}$ & $\begin{array}{l}\text { Cervera de } \\
\text { río Alhama }\end{array}$ & $\begin{array}{l}\text { Consejo de Castilla } \\
\text { Ayuntamiento }\end{array}$ & \\
\hline 1669 & 25.886 & Legajo & Pleito judicial & $\begin{array}{l}\text { Calahorra contra Aldeanueva por la } \\
\text { propiedad de un soto. }\end{array}$ & $\begin{array}{l}\text { Calahorra } \\
\text { Aldeanueva } \\
\text { de Ebro }\end{array}$ & $\begin{array}{l}\text { Consejo de Castilla } \\
\text { Ayuntamiento }\end{array}$ & \\
\hline
\end{tabular}




\begin{tabular}{|c|c|c|c|c|c|c|c|}
\hline 1670 & 25.906 & Legajo & Pleito judicial & $\begin{array}{l}\text { Concurso de acreedores contra los Propios } \\
\text { de Logroño }\end{array}$ & Logroño & $\begin{array}{l}\text { Ayuntamiento } \\
\text { Consejo de Castilla }\end{array}$ & \\
\hline 1670 & 3.207 & Libro & Asiento & $\begin{array}{l}\text { Varios vecinos profanan y queman la tumba } \\
\text { de Diego Gil Alfaro }\end{array}$ & Herce & Consejo de Castilla & $\begin{array}{l}\text { Diego Gil Alfaro (oidor } \\
\text { del Consejo de } \\
\text { Castilla) }\end{array}$ \\
\hline 1671 & 38.139 & Legajo & Pleito judicial & Proceso por contrabando de telas & Logroño & Consejo de Hacienda & $\begin{array}{l}\text { Pedro Igay Fernández } \\
\text { (mercader) }\end{array}$ \\
\hline 1671 & 51.347 & Legajo & Pleito judicial & $\begin{array}{l}\text { Denuncias mutuas entres varios clérigos y } \\
\text { el Obispado sobre la provisión de } \\
\text { benefiados en las parroquias. }\end{array}$ & Calahorra & $\begin{array}{l}\text { Parroquia de San Andrés } \\
\text { Parroquia de Santiago } \\
\text { Obispado }\end{array}$ & $\begin{array}{l}\text { Juan Urrutigoiti y Goñi } \\
\text { (Capellán de Honor de } \\
\text { S.M. y Arcediano de } \\
\text { Calahorra) }\end{array}$ \\
\hline 1671 & 25.946 & Legajo & Informe & $\begin{array}{l}\text { El alcalde mayor informa al Consejo sobre } \\
\text { los delitos cometidos por Diego Medrano }\end{array}$ & Calahorra & Consejo de Castilla & $\begin{array}{l}\text { Diego Medrano } \\
\text { Echáuz (caballero de } \\
\text { Santiago) } \\
\end{array}$ \\
\hline 1671 & 32.738 & Legajo & Pleito judicial & $\begin{array}{l}\text { Ejecutoria favorable al duque de Nájera en } \\
\text { el pleito con los vecinos de Cenicero. }\end{array}$ & $\begin{array}{l}\text { Cenicero } \\
\text { Navarrete } \\
\end{array}$ & $\begin{array}{l}\text { Consejo de Castilla } \\
\text { Ayuntamiento }\end{array}$ & Duque de Nájera \\
\hline 1671 & 28.083 & Legajo & Pleito judicial & $\begin{array}{l}\text { Atentado de varios vecinos contra don } \\
\text { Pedro Marin Rodezno }\end{array}$ & Nájera & Consejo de Castilla & Pedro Marin Rodezno \\
\hline 1671 & 25.922 & Legajo & Pleito judicial & $\begin{array}{l}\text { Calahorra contra el Cabildo de la Catedral } \\
\text { por la Canicería }\end{array}$ & Calahorra & $\begin{array}{l}\text { Consejo de Castilla } \\
\text { Ayuntamiento } \\
\text { Catedral de Calahorra }\end{array}$ & \\
\hline 1674 & $\begin{array}{l}2.776 \\
f .404\end{array}$ & Libro & $\begin{array}{l}\text { Consulta de } \\
\text { oficio }\end{array}$ & $\begin{array}{l}\text { Motín popular contra una compañia de } \\
\text { soldados alojados en la ciudad. }\end{array}$ & Logroño & Consejo de Guerra & \\
\hline 1674 & 26.331 & Legajo & $\begin{array}{l}\text { Juicio de } \\
\text { comisión }\end{array}$ & $\begin{array}{l}\text { Atentado contra el juez de comisión y } \\
\text { contrabando de moneda falsa. }\end{array}$ & Préjano & Consejo de Hacienda & $\begin{array}{l}\text { Miguel González } \\
\text { (contrabandista) }\end{array}$ \\
\hline 1674 & 28.204 & Legajo & Pleito judicial & $\begin{array}{l}\text { Concesión a perpetuidad del oficio de } \\
\text { alguacil mayor de la ciudad. }\end{array}$ & Alfaro & Consejo de Castilla & $\begin{array}{l}\text { José Rubio (alguacil } \\
\text { mayor) }\end{array}$ \\
\hline 1674 & 26.003 & Legajo & Pleito judicial & $\begin{array}{l}\text { La villa de Mansilla se niega a contribuir en } \\
\text { ta reparación de los puentes de Garray, } \\
\text { Verlanga, Tordomán y Cuzcurrita }\end{array}$ & \begin{tabular}{|l|} 
Mansilla \\
Cuzcurrita de \\
Rio Tirón \\
\end{tabular} & $\begin{array}{l}\text { Consejo de Castilla } \\
\text { Ayuntamiento }\end{array}$ & \\
\hline 1675 & 32.919 & Legajo & $\begin{array}{l}\text { Juicio de } \\
\text { comisión }\end{array}$ & Motín durante las elecciones municipales & $\begin{array}{l}\text { Torrecilla de } \\
\text { Cameros }\end{array}$ & $\begin{array}{l}\text { Consejo de Castilla } \\
\text { Ayuntamiento }\end{array}$ & \\
\hline 1676 & 26.448 & Legajo & $\begin{array}{l}\text { Juicio de } \\
\text { Comisión }\end{array}$ & $\begin{array}{l}\text { Procesamiento contra los cargos } \\
\text { municipales por corrupción }\end{array}$ & Cervera & Consejo de Castilla & $\begin{array}{l}\text { Juan Juaniz de Echáuz } \\
\text { (alcalde del crimen de } \\
\text { la Chancilleria de } \\
\text { Valladolid y juez de } \\
\text { comisión) } \\
\end{array}$ \\
\hline
\end{tabular}




\begin{tabular}{|c|c|c|c|c|c|c|c|}
\hline 1676 & 26.107 & Legajo & Pleito judicial & $\begin{array}{l}\text { Anulación del privilegio de Antoña Garcia, } \\
\text { por el que se eximia de tributos a varios } \\
\text { vecinos. }\end{array}$ & Cenicero & $\begin{array}{l}\text { Consejo de Castilla } \\
\text { Ayuntamiento }\end{array}$ & \\
\hline 1677 & 41.572 & Legajo & $\begin{array}{l}\text { Juicio de } \\
\text { residencia }\end{array}$ & Residencia al alcalde mayor de Alfaro & Alfaro & $\begin{array}{l}\text { Consejo de Castilla } \\
\text { Ayuntamiento }\end{array}$ & \\
\hline 1677 & 41.573 & Legajo & $\begin{array}{l}\text { Juicio de } \\
\text { residencia }\end{array}$ & Residencia al alcalde mayor de Alfaro & Alfaro & $\begin{array}{l}\text { Consejo de Castilla } \\
\text { Ayuntamiento }\end{array}$ & \\
\hline 1677 & 41.634 & Legajo & $\begin{array}{l}\text { Juicio de } \\
\text { residencia }\end{array}$ & Residencia al alcalde mayor de Calahorra & Calahorra & $\begin{array}{l}\text { Consejo de Castilla } \\
\text { Ayuntamiento }\end{array}$ & \\
\hline 1677 & 27.965 & Legajo & Pleito judicial & El concejo contra el duque de Béjar & $\begin{array}{l}\text { Santo } \\
\text { Domingo de } \\
\text { la Calzada }\end{array}$ & $\begin{array}{l}\text { Ayuntamiento } \\
\text { Consejo de Castilla }\end{array}$ & Duque de Béjar \\
\hline 1678 & 28.104 & Legajo & Pleito judicial & Reparación del puente & Haro & $\begin{array}{l}\text { Consejo de Castilla } \\
\text { Ayuntamiento }\end{array}$ & \\
\hline 1679 & 28.108 & Legajo & Pleito judicial & Haro contra Casalarreina & $\begin{array}{l}\text { Haro } \\
\text { Casalarreina } \\
\end{array}$ & $\begin{array}{l}\text { Consejo de Castilla } \\
\text { Ayuntamiento }\end{array}$ & \\
\hline 1679 & 26.144 & Legajo & Pleito judicial & Consumo de una escribanía & Cenicero & $\begin{array}{l}\text { Consejo de Castilla } \\
\text { Ayuntamiento }\end{array}$ & \\
\hline 1680 & 36.589 & Legajo & Pleito judicial & $\begin{array}{l}\text { Separación matrimonial y denuncia por } \\
\text { impago de la pensión. }\end{array}$ & $\begin{array}{l}\text { Logroño } \\
\text { Herce }\end{array}$ & $\begin{array}{l}\text { Consejo de Castilla } \\
\text { Convento de Santa María } \\
\text { la Real de Herce }\end{array}$ & $\begin{array}{l}\text { Hipólita Escarza } \\
\text { Pedro lgay Fernández } \\
\text { (mercader) }\end{array}$ \\
\hline 1681 & 26.179 & Legajo & $\begin{array}{l}\text { Juicio de } \\
\text { comisión }\end{array}$ & Libelos contra el corregidor & Logroño & $\begin{array}{l}\text { Corregimiento } \\
\text { Consejo de Castilla }\end{array}$ & \\
\hline 1681 & 26.254 & Legajo & $\begin{array}{l}\text { Juicio de } \\
\text { comisión }\end{array}$ & Libelos contra el corregidor & Logroño & $\begin{array}{l}\text { Consejo de Castilla } \\
\text { Corregimiento }\end{array}$ & $\begin{array}{l}\text { Francisco Martinez } \\
\text { Mata (alcalde mayor y } \\
\text { juez pesquisidor) } \\
\text { Pedro Velluti de Haro } \\
\text { (corregidor) } \\
\end{array}$ \\
\hline 1681 & 26.225 & Legajo & Pleito judicial & $\begin{array}{l}\text { Solicitud de roturar } 200 \text { fanegas de montes } \\
\text { comunales }\end{array}$ & \begin{tabular}{|l|} 
Muro de \\
Cameros \\
\end{tabular} & $\begin{array}{l}\text { Consejo de Castilla } \\
\text { Ayuntamiento } \\
\end{array}$ & \\
\hline 1682 & 38.188 & Legajo & Pleito judicial & $\begin{array}{l}\text { El conde de Aguilar denuncia a varias villas } \\
\text { por impedir el trabajo de sus recaudadores }\end{array}$ & $\begin{array}{l}\text { Cervera } \\
\text { Condado de } \\
\text { Aguilar }\end{array}$ & $\begin{array}{l}\text { Consejo de Castilla } \\
\text { Chancilleria de Valladolid }\end{array}$ & $\begin{array}{l}\text { Iñigo Ramirez de } \\
\text { Arellano (Conde de } \\
\text { Aguilar) } \\
\text { Juan Francisco } \\
\text { Romero (Administrador } \\
\text { del Conde de Aguilar) } \\
\end{array}$ \\
\hline 1682 & 41.360 & Legajo & Pleito judicial & $\begin{array}{l}\text { Concurso de acreedores contra los bienes } \\
\text { de un noble. }\end{array}$ & Logroño & Consejo de Castilla & $\begin{array}{l}\text { José Castejón y } \\
\text { Mendoza (Señor de } \\
\text { Soto y Treguajantes) }\end{array}$ \\
\hline 1683 & 34.022 & Legajo & Pleito judicial & $\begin{array}{l}\text { Resistencias de la población contra las } \\
\text { autoridades señoriales }\end{array}$ & Cañas & $\begin{array}{l}\text { Ayuntamiento } \\
\text { Consejo de Castilla }\end{array}$ & $\begin{array}{l}\text { Pedro Manso de } \\
\text { Zúñiga (señor de } \\
\text { Cañas) }\end{array}$ \\
\hline
\end{tabular}




\begin{tabular}{|c|c|c|c|c|c|c|c|}
\hline 1683 & 28.116 & Legajo & Pleito judicial & Reparación del puente & Haro & $\begin{array}{l}\text { Consejo de Castilla } \\
\text { Ayuntamiento }\end{array}$ & \\
\hline 1685 & 38.189 & Legajo & $\begin{array}{l}\text { Juicio de } \\
\text { comisión }\end{array}$ & Motín antiseñorial & Cenicero & $\begin{array}{l}\text { Consejo de Hacienda } \\
\text { Ayuntamiento }\end{array}$ & $\begin{array}{l}\text { Duquesa de Nájera } \\
\text { Agustin Perpiñán (juez } \\
\text { de comisión) } \\
\text { Pedro Gómez Elgueta } \\
\text { (Administrador de las } \\
\text { alcabalas de la } \\
\text { Duquesa) } \\
\end{array}$ \\
\hline 1685 & 28.118 & Legajo & Pleito judicial & Pleito entre eclesiásticos & $\begin{array}{l}\text { Leza de río } \\
\text { Leza }\end{array}$ & Consejo de Castilla & \\
\hline 1686 & 34.019 & Legajo & Pleito judicial & Proceso por contrabando & Logroño & Consejo de Hacienda & \\
\hline 1686 & 26.254 & Legajo & $\begin{array}{l}\text { Juicio de } \\
\text { comisión }\end{array}$ & Libelos contra el corregidor & Logroño & $\begin{array}{l}\text { Consejo de Castilla } \\
\text { Corregimiento }\end{array}$ & \\
\hline 1686 & $\begin{array}{l}2.776 \\
f .425\end{array}$ & Libro & $\begin{array}{l}\text { Consulta de } \\
\text { Oficio }\end{array}$ & $\begin{array}{l}\text { Muerte del alguacil mayor y varios vecinos } \\
\text { en un enfrentamiento con tropas alojadas } \\
\text { en la ciudad }\end{array}$ & Calahorra & Consejo de Castilla & \\
\hline 1686 & 3.199 & Libro & Asiento & Atentado y falsificación de moneda & Préjano & Consejo de Castilla & \\
\hline 1686 & 41.571 & Legajo & $\begin{array}{l}\text { Juicio de } \\
\text { residencia }\end{array}$ & Residencia al alcalde mayor de Calahorra & Calahorra & $\begin{array}{l}\text { Consejo de Castilla } \\
\text { Ayuntamiento }\end{array}$ & \\
\hline 1686 & 51.349 & Legajo & Pleito judicial & $\begin{array}{l}\text { El corregidor de Santo Domingo contra un } \\
\text { clérigo que protegió a varios galeotes } \\
\text { fugados }\end{array}$ & $\begin{array}{l}\text { Santo } \\
\text { Domingo de } \\
\text { la Calzada }\end{array}$ & $\begin{array}{l}\text { Corregimiento } \\
\text { Consejo de Castilla }\end{array}$ & \\
\hline 1687 & 26.337 & Legajo & Pleito judicial & Lucha de bandos. Agresión a un vecino. & $\begin{array}{l}\text { Murillo de } \\
\text { Calahorra }\end{array}$ & Consejo de Castilla & Juan Martinez Lacarra \\
\hline 1687 & 34.019 & Legajo & Pleito judicial & $\begin{array}{l}\text { Conflicto por el alojamiento de tropas en la } \\
\text { ciudad }\end{array}$ & Logroño & $\begin{array}{l}\text { Corregimiento } \\
\text { Consejo de Hacienda }\end{array}$ & $\begin{array}{l}\text { Vizconde de Amaya } \\
\text { (corregidor) }\end{array}$ \\
\hline 1687 & $\begin{array}{l}2.776 \\
f .442 v \text {. }\end{array}$ & Libro & Real Decreto & $\begin{array}{l}\text { Liberación del capitán implicado en el motín } \\
\text { de } 1674\end{array}$ & Logroño & Consejo de Guerra & \\
\hline 1687 & $\begin{array}{l}13.216 \\
\text { Exp. } n^{\circ} 50\end{array}$ & Legajo & Expediente & $\begin{array}{l}\text { Decreto de gracia permitiendo entrar pan de } \\
\text { Navarra en Logroño }\end{array}$ & Logroño & $\begin{array}{l}\text { Aduana de Logroño } \\
\text { Consejo de Castilla } \\
\text { Ayuntamiento }\end{array}$ & \\
\hline 1687 & 27.928 & Legajo & Pleito judicial & $\begin{array}{l}\text { Alfaro contra Cintruénigo por el reparto del } \\
\text { agua de riego del Alhama. }\end{array}$ & Alfaro & $\begin{array}{l}\text { Consejo de Castilla } \\
\text { Ayuntamiento }\end{array}$ & \\
\hline 1687 & 42.597 & Legajo & $\begin{array}{l}\text { Juicio de } \\
\text { residencia }\end{array}$ & Al alcalde mayor de Alfaro & Alfaro & Consejo de Castilla & \\
\hline 1687 & $\begin{array}{l}42.486 \\
42.487 \\
42.599 \\
42.671 \\
42.717 \\
\end{array}$ & Legajo & $\begin{array}{l}\text { Juicio de } \\
\text { residencia }\end{array}$ & Al alcalde mayor de Calahorra & Calahorra & $\begin{array}{l}\text { Consejo de Castilla } \\
\text { Ayuntamiento }\end{array}$ & \\
\hline
\end{tabular}




\begin{tabular}{|c|c|c|c|c|c|c|c|}
\hline 1687 & 26.266 & Legajo & Pleito judicial & $\begin{array}{l}\text { La villa contra el convento de Valvanera } \\
\text { sobre el derecho a cortar leña }\end{array}$ & Ventrosa & $\begin{array}{l}\text { Convento de Valvanera } \\
\text { Ayuntamiento } \\
\text { Consejo de Castilla }\end{array}$ & \\
\hline 1688 & 41.585 & Legajo & Inventario & Censo de cubas de Logroño & Logroño & $\begin{array}{l}\text { Consejo de Hacienda } \\
\text { Ayuntamiento }\end{array}$ & \\
\hline 1688 & 15.661 & Legajo & Real Cédula & $\begin{array}{l}\text { Obras en la Sacristia de la Redonda, con la } \\
\text { oposición de la Capilla del Santo Cristo. }\end{array}$ & Logroño & $\begin{array}{l}\text { Real Patronato } \\
\text { Consejo de Castilla } \\
\text { lglesia de Santa Maria de } \\
\text { la Redonda } \\
\text { Real Capilla del Santo } \\
\text { Cristo } \\
\end{array}$ & $\begin{array}{l}\text { Vizconde de Amaya } \\
\text { (corregidor) } \\
\text { Pedro Gonzalez del } \\
\text { Castillo (Obispo de } \\
\text { Calahorra) }\end{array}$ \\
\hline 1688 & 41.625 & Legajo & $\begin{array}{l}\text { Juicio de } \\
\text { comisión }\end{array}$ & $\begin{array}{l}\text { Investigación sobre la gestión de una obra } \\
\text { pia para casar doncellas }\end{array}$ & Logroño & $\begin{array}{l}\text { Ayuntamiento } \\
\text { Consejo de Castilla }\end{array}$ & $\begin{array}{l}\text { Juan Vélez de } \\
\text { Guevara (Licenciado) }\end{array}$ \\
\hline 1688 & $\begin{array}{l}32.803 \\
32.804\end{array}$ & Legajo & $\begin{array}{l}\text { Juicio de } \\
\text { residencia }\end{array}$ & $\begin{array}{l}\text { Residencia al corregidor y oficiales del } \\
\text { concejo }\end{array}$ & $\begin{array}{l}\text { Santo } \\
\text { Domingo de } \\
\text { la Calzada }\end{array}$ & $\begin{array}{l}\text { Consejo de Castilla } \\
\text { Ayuntamiento } \\
\text { Corregimiento } \\
\end{array}$ & \\
\hline 1689 & 26.387 & Legajo & $\begin{array}{l}\text { Juicio de } \\
\text { comisión }\end{array}$ & $\begin{array}{l}\text { Abusos de los regidores en el reparto de los } \\
\text { impuestos }\end{array}$ & Alberite & $\begin{array}{l}\text { Consejo de Castilla } \\
\text { Ayuntamiento }\end{array}$ & \\
\hline 1689 & 23.891 & Legajo & Petición & $\begin{array}{l}\text { La villa solicita no contribuir en los } \\
\text { repartimientos para arreglar puentes }\end{array}$ & Ezcaray & $\begin{array}{l}\text { Consejo de Castilla } \\
\text { Ayuntamiento }\end{array}$ & \\
\hline 1689 & 27.864 & Legajo & Pleito judicial & $\begin{array}{l}\text { Cervera contra el Convento de Fitero por el } \\
\text { riego con agua del Alhama }\end{array}$ & Cervera & $\begin{array}{l}\text { Consejo de Castilla } \\
\text { Convento de Fitero } \\
\text { Ayuntamiento } \\
\end{array}$ & \\
\hline 1690 & 26.331 & Legajo & Pleito judicial & Un clérigo es acusado de violación & Năjera & Consejo de Castilla & $\begin{array}{l}\text { María Lisarre } \\
\text { Andrés del Castillo } \\
\text { (clérigo) }\end{array}$ \\
\hline 1690 & 28.123 & Legajo & Pleito judicial & El concejo contra el médico de la ciudad & Alfaro & $\begin{array}{l}\text { Consejo de Castilla } \\
\text { Ayuntamiento }\end{array}$ & \\
\hline 1691 & 26.331 & Legajo & Pleito judicial & $\begin{array}{l}\text { La vilia contra su señor por la venta de la } \\
\text { jurisdicción de tolerancia y malos tratos a } \\
\text { los vecinos } \\
\end{array}$ & $\begin{array}{l}\text { Soto de } \\
\text { Cameros }\end{array}$ & $\begin{array}{l}\text { Consejo de Castilla } \\
\text { Ayuntamiento }\end{array}$ & $\begin{array}{l}\text { Juan Mateo Hurtado } \\
\text { de Mendoza (señor de } \\
\text { Soto) }\end{array}$ \\
\hline 1691 & 26.362 & Legajo & $\begin{array}{l}\text { Juicio de } \\
\text { Comisión }\end{array}$ & $\begin{array}{l}\text { Pesquisa contra el Contador del Condado } \\
\text { de Aguilar y sus parciales por corrupción y } \\
\text { abusos de poder. }\end{array}$ & $\begin{array}{l}\text { Viguera } \\
\text { Ribafrecha } \\
\text { Medrano } \\
\end{array}$ & $\begin{array}{l}\text { Consejo de Castilla } \\
\text { Condado de Aguilar }\end{array}$ & $\begin{array}{l}\text { Francisco Romero } \\
\text { (Contador del Conde } \\
\text { de Aguilar). }\end{array}$ \\
\hline 1693 & 25.370 & Legajo & $\begin{array}{l}\text { Visita de } \\
\text { escribanos }\end{array}$ & Procesamiento de varios escribanos & Logroño & Consejo de Castilla & $\begin{array}{l}\text { Santiago de la Torre } \\
\text { (juez visitador) }\end{array}$ \\
\hline 1693 & 41.480 & Legajo & $\begin{array}{l}\text { Juicio de } \\
\text { comisión }\end{array}$ & Excesos del corregidor de la ciudad & $\begin{array}{l}\text { Santo } \\
\text { Domingo de } \\
\text { la Calzada }\end{array}$ & Consejo de Castilla & \\
\hline 1695 & 3.226 & Libro & Asiento & $\begin{array}{l}\text { El duque se queja de que los vecinos han } \\
\text { maltratado a su administrador. }\end{array}$ & Nájera & Consejo de Castilla & Duque de Nájera \\
\hline
\end{tabular}




\begin{tabular}{|c|c|c|c|c|c|c|c|}
\hline 1695 & 3.319 & Libro & Asiento & Tumultos en Arnedo & Arnedo & Consejo de Castilla & $\begin{array}{l}\text { Ldo. Luis Ycháus } \\
\text { (oidor de la Audiencia } \\
\text { de Navarra) }\end{array}$ \\
\hline 1695 & 23.905 & Legajo & Pleito judicial & $\begin{array}{l}\text { Pleito por el nombramiento de un regidor } \\
\text { del concejo }\end{array}$ & $\begin{array}{l}\text { Arenzana de } \\
\text { Abajo }\end{array}$ & $\begin{array}{l}\text { Ayuntamiento } \\
\text { Consejo de Castilla }\end{array}$ & \\
\hline 1696 & 29.311 & Legajo & Pleito judicial & $\begin{array}{l}\text { Intento de consumo de los oficios de } \\
\text { regidores perpetuos. }\end{array}$ & Logroño & $\begin{array}{l}\text { Consejo de Castilla } \\
\text { Ayuntamiento }\end{array}$ & \\
\hline 1696 & 23.911 & Legajo & Pleito judicial & $\begin{array}{l}\text { Disputas con el duque sobre la forma de } \\
\text { cobrar los impuestos. }\end{array}$ & Nájera & $\begin{array}{l}\text { Consejo de Castilla } \\
\text { Ayuntamiento }\end{array}$ & Duque de Nájera \\
\hline 1696 & 23.911 & Legajo & Pleito judicial & $\begin{array}{l}\text { El común contra los regidores por la forma } \\
\text { de repartir los impuestos. }\end{array}$ & Nájera & $\begin{array}{l}\text { Consejo de Castilla } \\
\text { Ayuntamiento }\end{array}$ & \\
\hline 1696 & 23.911 & Legajo & Pleito judicial & Disputas entre bandos de regidores & Nájera & $\begin{array}{l}\text { Consejo de Castilla } \\
\text { Ayuntamiento }\end{array}$ & \\
\hline 1696 & 32.968 & Legajo & Pleito judicial & $\begin{array}{l}\text { Segregación de la jurisdicción de Nájera de } \\
\text { las villas de Tricio y Cenicero }\end{array}$ & $\begin{array}{l}\text { Nájera } \\
\text { Tricio } \\
\text { Cenicero }\end{array}$ & $\begin{array}{l}\text { Consejo de Castilla } \\
\text { Ayuntamiento }\end{array}$ & \\
\hline 1696 & 23.909 & Legajo & Pleito judicial & $\begin{array}{l}\text { La ciudad contra el Obispo por el vicario del } \\
\text { Obispado. }\end{array}$ & Alfaro & $\begin{array}{l}\text { Obispado de Tarazona } \\
\text { Ayuntamiento }\end{array}$ & \\
\hline 1697 & 42.716 & Legajo & Pleito judicial & Pleito por los pastos comunes de la ciudad. & $\begin{array}{l}\text { Santo } \\
\text { Domingo de } \\
\text { la Calzada }\end{array}$ & Consejo de Castilla & \\
\hline
\end{tabular}

